\title{
Preparation of High Purity, High Molecular-Weight Chitin from Ionic Liquids for Use as an Adsorbate for the Extraction of Uranium from Seawater
}

\section{Fuel Cycle R\&D}

Dr. Robin Rogers University of Alabama

Stephen Kung, Federal POC Sheng Dai, Technical POC 


\section{DOE-NEUP FINAL REPORT}

Project Title:

Functionalized High Molecular Weight Chitinous Nanofibers from Direct Extraction of Shrimp Shells for Novel Uranium from Seawater Sorbents

Principal Investigator:

Robin D. Rogers

Center for Green Manufacturing and Department of Chemistry, The University of Alabama, Tuscaloosa, AL 35487

Tel: (205) 348-4323; Email: rdrogers@ua.edu

\section{Reporting Period:}

Oct. 1, 2011 - October 18, 2013

Report Prepared by: Patrick S. Barber and Robin D. Rogers 


\section{Table of Contents}

$\begin{array}{ll}\text { Title Page } & 1\end{array}$

$\begin{array}{ll}\text { Table of Contents } & 2\end{array}$

$\begin{array}{ll}\text { I. Abstract } & 3\end{array}$

II. Scope and Aims $\quad 4$

III. Technical Summary of the Work Accomplished 5

A. Highly selective extraction of the uranyl ion with hydrophobic amidoximefunctionalized ionic liquids via $\eta^{2}$ coordination.

B. Electrospinning of chitin nanofibers directly from an ionic liquid extract of shrimp shells.

C. Coagulation of chitin and cellulose from 1-ethyl-3-methylimidazolium acetate ionic-liquid solutions using carbon dioxide.

D. Surface modification of chitin fibers spun from ionic liquid solution: a versatile platform with the strength of chitin and the surface functionality of chitosan.

E. Extraction of uranium from seawater using surface modified chitin fibers; in collaboration with PNNL.

F. Scale up and development of continuous chitin extraction using flow through microwave.

IV. Summary of Major Achievements

V. Collaborations

$\begin{array}{ll}\text { VI. Publications } & 22\end{array}$

$\begin{array}{ll}\text { VII. Presentations } & 22\end{array}$

$\begin{array}{ll}\text { VIII. Media } & 23\end{array}$

$\begin{array}{ll}\text { IX. References } & 24\end{array}$ 


\section{Abstract}

The key goal of this research program is to develop an efficient and cost effective chitinbased sorbent for uranium from seawater prepared from shellfish waste. Using the unprecedented control over chitin fiber production made possible by an ionic liquid based process, we proposed to graft uranium selective moieties onto chitin fibers. Advantages of this approach include 1) saving energy over the current industrial processes by directly obtaining the chitin from shellfish waste, 2) the potential for continuous processing of high surface area nanofibers in an economical operation, 3) a unique, high molecular weight chitin not available from the current industrial process which may lead to a stronger, more durable adsorbent, and 4) easy chemical modification of the large surface area adsorbent with uranyl selective functionality. The use of a waste product as a feedstock also gives the chitin based sorbent a net economic and energy gain due to offsetting the costs of disposing shellfish waste from the seafood industry and creating a market for crustacean shells.

During the last several years, the potential of an IL-based platform for generating high surface area, renewable chitin-based sorbents has been investigated. The fundamental chemistry of appending the highly-selective amidoxime moiety onto an IL was developed, and hydrophobic, amidoxime-functionalized imidazolium based ILs were used to extract uranium selectively from aqueous solutions and determine the coordination mode of amidoxime with the uranyl ion. Electrospinning of chitin nanofibers directly from a solution of raw shrimp shell in ILs was demonstrated for the first time and found to depend on several key interactions between the viscosity, concentration, and entanglement density of the solutions only available with ILs. One of the key economic issues of using ionic liquids, the need for recycling, was explored through the use of super-critical carbon dioxide as a coagulation solvent for chitin from a chitin extract solution in ionic liquid. Finally, the uranium uptake of chitin fibers spun from IL solutions of chitin extract was found to be significantly enhanced by surface-functionalizing these fibers with amidoxime groups. This was supported in aqueous solutions and in actual marine testing. Together, these findings have proven the utilization of ionic liquids as an effective platform for preparing a high surface area, chemically versatile adsorbent material from a renewable source. 


\section{Scope and Aims of the Proposed Work}

The overall goal of this research is to develop a fundamental understanding of the chemistry and engineering needed to prepare an efficient and cost effective chitin-based sorbent for extraction of uranium from seawater, by combining selective uranium extraction techniques with high-surface area chitin nanofibers. The work will be divided into four important and different concurrent tasks. These include 1) demonstrating continuous extraction/spinning processing of chitin or chitin blend nanofibers of very high surface area and in specific architectures; 2) developing the appropriate chemistry to chemically modify the fiber surfaces with selective uranium extractant capacity; 3) understanding the key chemical and engineering variables of both extraction efficiency, capacity, and stripping and of fiber cost and durability, and 4) demonstrating the direct extraction and recovery of uranium from seawater simulants and ultimately the Gulf of Mexico. Three key scientific challenges must be overcome in this effort: obtaining very high uranium selectivity, developing efficient recovery and recycle methods, and preparing chitinous materials that are stable in seawater for extended periods.

These challenges were logically approached and reported through a series of publications that were focused on the fundamental chemistry necessary for the development and success of the proposed work, including the development of the chemistry for an amidoxime functionalized ionic liquid and the isolation of the mechanism of uranium extraction by amidoxime (RSC Adv. 2012, 2, 8526-8530), the development and first instance of electrospinning chitin nanofibers using ionic liquids (Green Chem. 2013, 15, 601-607), the development of biopolymers coagulation and recycling of ionic liquids, one of the key economic issues for the use of ionic liquids in biomass extraction (Angew. Chem. Int. Ed. 2013, 52, 12350-12353), and the development of a dry wet-spun chitin fiber modified on the surface with amidoxime and demonstration of the extraction of uranium from aqueous solution. 


\section{Technical Summary of the Work Accomplished}

A. Highly selective extraction of the uranyl ion with hydrophobic amidoximefunctionalized ionic liquids via $\eta 2$ coordination.

Barber, P. S.; Kelley, S. P.; Rogers, R. D. Highly selective extraction of the uranyl ion with hydrophobic amidoxime-functionalized ionic liquids via $\eta 2$ coordination. $R S C A d v .2012,2$, 8526-8530.

We sought to investigate the mechanism for the selectivity of amidoxime for uranyl ions in seawater as well as develop methods for chemically modifying chitin with amidoxime groups. We first incorporated an amidoxime coordination site within a hydrophobic IL to directly explore the fundamental aspects of chemical modification as well as the coordination and separation of the uranyl cation.

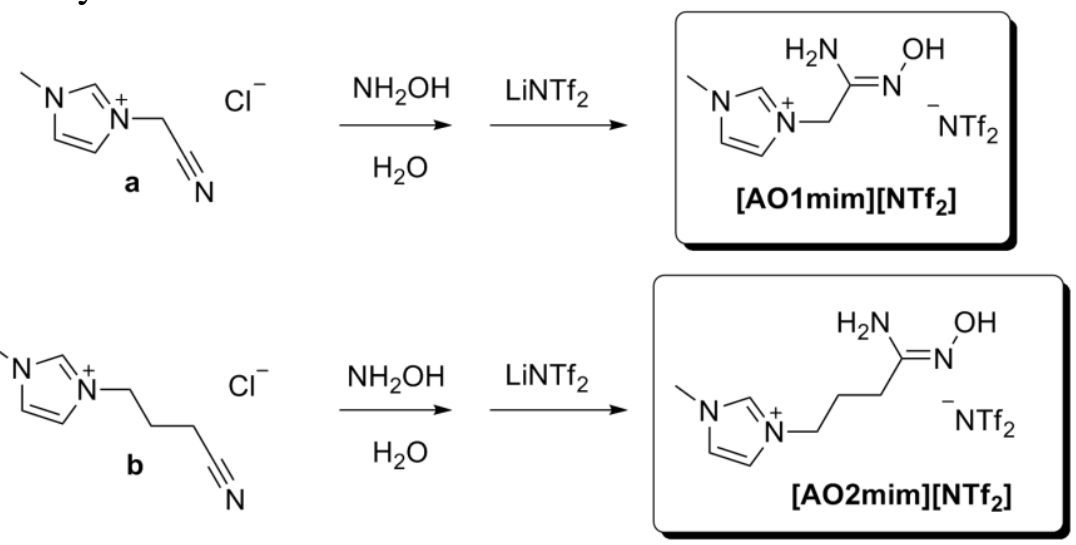

Scheme 1. The synthetic approach for hydrophobic, amidoxime-functionalized ionic liquids.

Two amidoxime functionalized ILs were synthesized by a three- step, two-pot reaction in moderately high yields (Scheme 1). The alkylation of 1-methylimidazole with either chloroacetonitrile or 4-chlorobutanenitrile gave the corresponding cyano-derivatized IL intermediates $\mathbf{a}$ and $\mathbf{b} .{ }^{1}$ Treating the intermediates with excess hydroxylamine in water yielded ILs as the chloride salts, which then phase-separated with the addition of $\operatorname{LiNTf}_{2}$ as molten bis(trifluoromethane)sulfonamide salts, [AO1mim] $\left[\mathrm{NTf}_{2}\right]$ and $[\mathrm{AO} 2 \mathrm{mim}]\left[\mathrm{NTf}_{2}\right]$.

By taking advantage of their hydrophobic properties, we conducted aqueous extractions to show the selectivity of the ILs for $\mathrm{UO}_{2}{ }^{2+}, \mathrm{Eu}^{3+}$, and $\mathrm{Th}^{4+}$. We found the selectivity for the ILs as $\mathrm{UO}_{2}{ }^{2+}>\mathrm{Th}^{4+}>\mathrm{Eu}^{3+}$ with separation factors $(\mathrm{SF})$ of $\mathrm{SF}_{(\mathrm{UO} 2 / \mathrm{Th})}=4.6, \mathrm{SF}_{(\mathrm{UO} 2 / \mathrm{Eu})}=8.2$, and $\mathrm{SF}_{(\mathrm{Th} / \mathrm{Eu})}=1.8$ for $[\mathrm{AO} 1 \mathrm{mim}]\left[\mathrm{NTf}_{2}\right]$ and $11.4,480$, and 42 for $[\mathrm{AO} 2 \mathrm{mim}]\left[\mathrm{NTf}_{2}\right]$. The extraction of the uranyl ion was also studied (Figure 1) as a function of nitric acid concentration and sodium nitrate concentrations and indicated that with increasing acid concentration the distribution values decreased significantly, while a change in concentration of the nitrate anion proceeded differently for each IL. This suggested that there was a possible difference in the mechanism between the two similar ILs. 

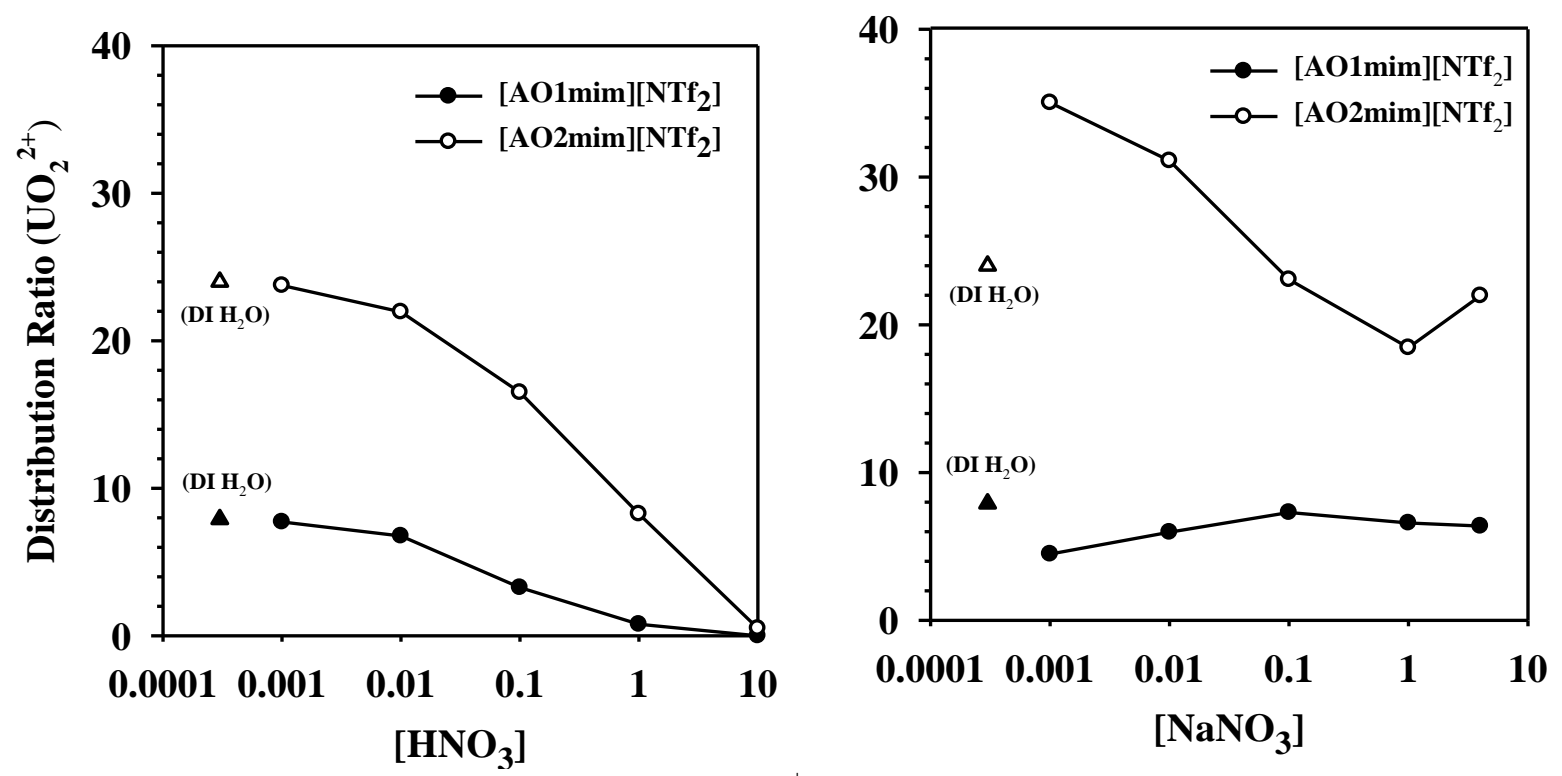

Figure 1. Distribution ratios as a function of $\left[\mathrm{H}^{+}\right]$(left) and $\left[\mathrm{NO}_{3}{ }^{-}\right]$(right) for $[\mathrm{AO} 1 \mathrm{mim}]\left[\mathrm{NTf}_{2}\right]$ $(\bullet)$ and $[\mathrm{AO} 2 \mathrm{mim}]\left[\mathrm{NTf}_{2}\right](\mathrm{O})$.

Through reacting these ILs with uranyl nitrate, we were able to isolate single crystals and determine the crystal structure of the complex shown in Figure 2. From this we were able to observe deprotonated amidoximate bonded to the uranyl center in an $\eta^{2}$ coordination mode, as reported by Hay and coworkers for amidoximate systems. ${ }^{2}$ In total, this study verified our approach for grafting amidoxime functional groups onto an amine, showed us the selectivity enhancement of incorporating amidoxime functionality into the receiving phase, and produced evidence for the extraction mechanism of the amidoxime polymers that have been successfully employed in the extraction of uranium from seawater.
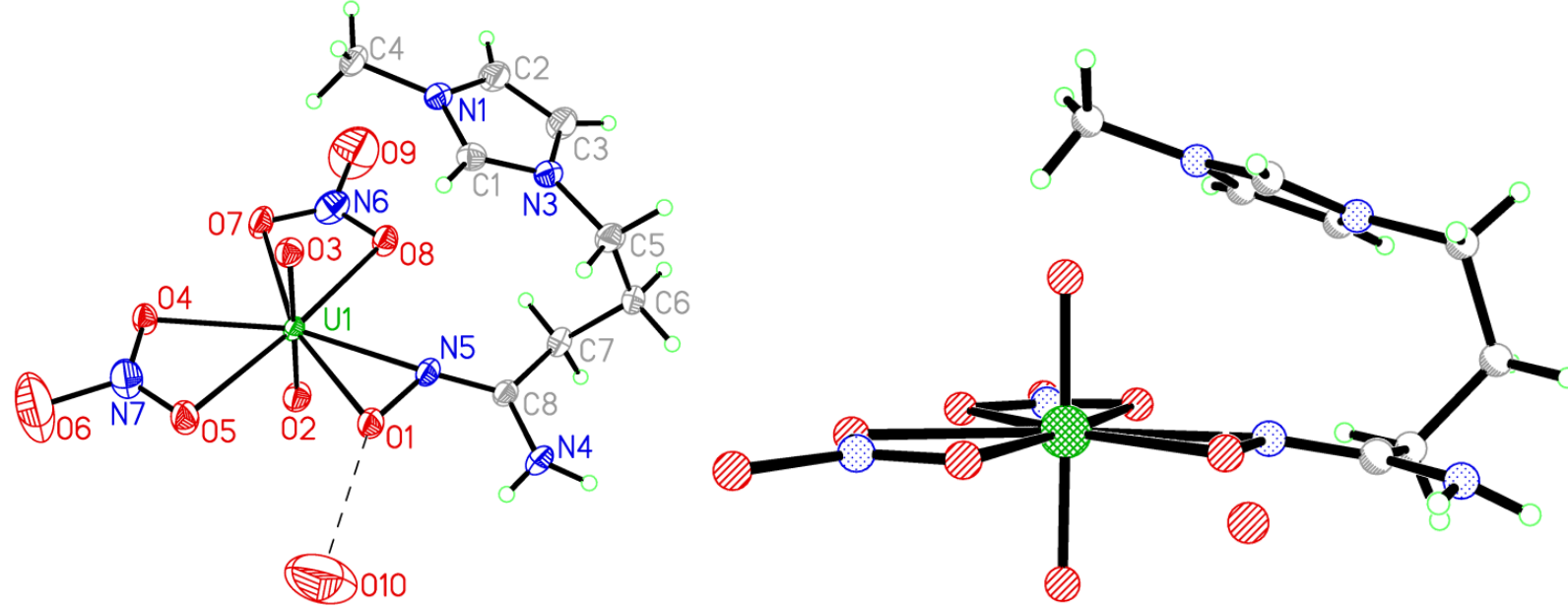

Figure 2. Two views of the hexagonal bipyramidal coordination geometry around uranium in $\left[\mathrm{UO}_{2}\left(\mathrm{NO}_{3}\right)_{2}\right.$ (1-(4-amidoximate)butyl)-3-methyl-imidazolium] $\cdot \mathrm{H}_{2} \mathrm{O}$ (50\% probability ellipsoids). 


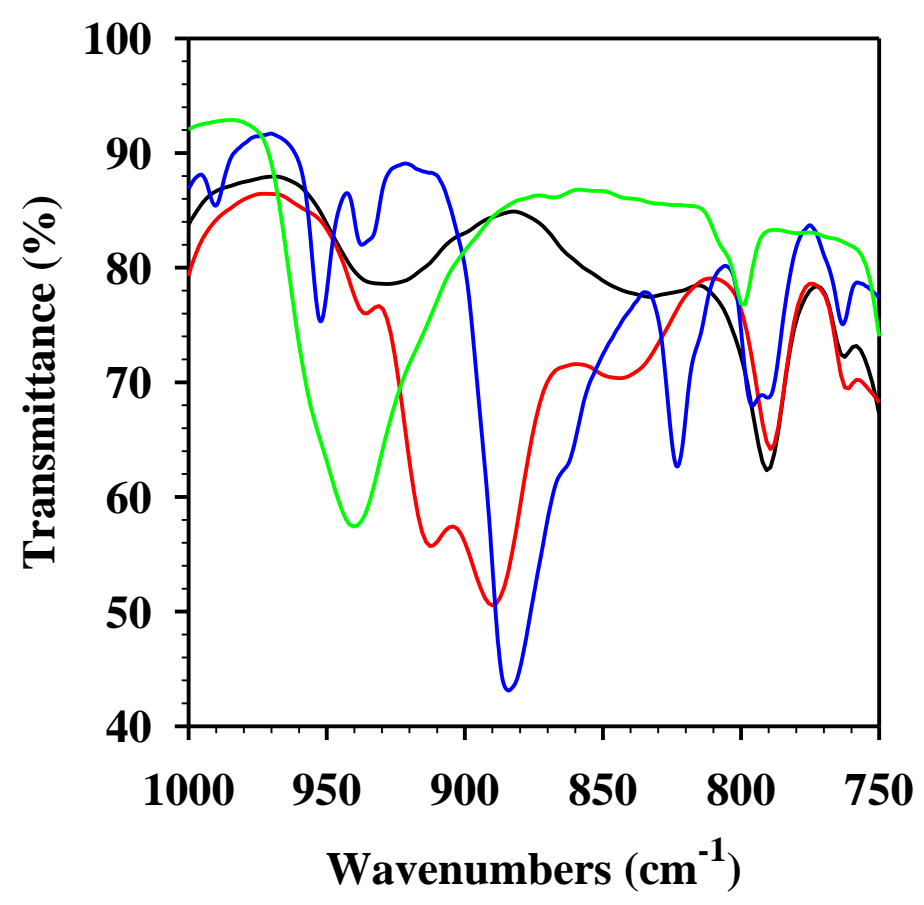

Figure 3. Infrared spectra comparing $[\mathrm{AO} 2 \mathrm{mim}]\left[\mathrm{NTf}_{2}\right]$ (black), $[\mathrm{AO} 2 \mathrm{mim}]\left[\mathrm{NTf}_{2}\right]$ with $\mathrm{UO}_{2}\left(\mathrm{NO}_{3}\right)_{2}$ (red), $\mathrm{UO}_{2}\left(\mathrm{NO}_{3}\right)_{2}$ hexahydrate (green), and crystals of $\left[\mathrm{UO}_{2}\left(\mathrm{NO}_{3}\right)_{2}\right.$ (3-(4amidoximate)butyl)-1-methyl-imidazolium)] monohydrate.(blue).

The infrared (IR) spectrum of crystalline $\mathrm{UO}_{2}\left(\mathrm{NO}_{3}\right)_{2}(\mathrm{AO} 2 \mathrm{mim}) \cdot \mathrm{H}_{2} \mathrm{O}$ was compared to the IR spectrum of a methanol solution containing a mixture of $[\mathrm{AO} 2 \mathrm{mim}]\left[\mathrm{NTf}_{2}\right]$ with uranyl nitrate hexahydrate in order to determine if the IL complexes with uranyl in solution. Figure 3 shows the region of the IR spectra which contains the characteristic asymmetric uranyl $\mathrm{U}=\mathrm{O}$ stretch, which can be used to distinguish the uranyl complexes from each other. This $\mathrm{U}=\mathrm{O}$ stretch in $\mathrm{UO}_{2}\left(\mathrm{NO}_{3}\right)_{2}(\mathrm{AO} 2 \mathrm{mim})\left(886 \mathrm{~cm}^{-1}\right)$ is red-shifted relative to the same stretch in uranyl nitrate hexahydrate $\left(943 \mathrm{~cm}^{-1}\right)$, which is consistent with the replacement of the neutral water molecules by more strongly donating anionic amidoximate ligands. The solution shows a strong IR band at $893 \mathrm{~cm}^{-1}$, indicating that the amidoximate moiety coordinates in solution as well noted by the indicative red shift.

We have synthesized two new amidoxime-functionalized, hydrophobic ionic liquids in a simple three-step process. The phase miscibility with water, extraction behavior, IR data, and solid state characterization support an $\eta^{2}$ amidoximate coordination mechanism for the extraction of $\mathrm{UO}_{2}{ }^{2+}$ from aqueous solutions. The high distribution ratios for $\mathrm{UO}_{2}{ }^{2+}$ provide high selectivity over $\mathrm{Th}^{4+}$ and $\mathrm{Eu}^{3+}$ suggesting these ILs could play a role in the separation of uranium from nuclear waste. In total, this study provides evidence of the extraction mechanism of the amidoxime polymers that have been successful employed in the extraction of uranium from seawater. 


\section{B. Electrospinning of chitin nanofibers directly from an ionic liquid extract of shrimp shells.}

Barber, P. S.; Griggs, C. S.; Bonner, J. R.; Rogers, R. D. Electrospinning of chitin nanofibers directly from an ionic liquid extract of shrimp shells. Green Chem. 2013, 15, 601-607.

The electrospinning of chitin into high surface area nanofibers or high porosity nanomaterials is perhaps one of the most exciting new possibilities made available by the dissolution of biomass in ionic liquid. ${ }^{3,4,5}$ Electrospinning uses an electric field to pull micron and nano-sized fibers from a polymer solution. A solution containing the polymer is pushed through a charged spinneret where a high electric potential causes the drop of polymer solution to form a Taylor cone. Under the right conditions, a viscous jet of polymer is then ejected towards a collecting electrode, deforming into a nanoscale-width fiber in the process. ${ }^{6}$ The system balances polymer entanglement density, solution viscosity, and surface tension to prevent beads and create smooth, continuous fibers. ${ }^{7}$ For solution in volatile solvents, the solvent then evaporates and concentrates the polymer solution which allows for the fibers to form on the electrode. However, the ionic liquids used here are non-volatile. Therefore, a coagulation bath is used for the precipitation of the chitin and the dissolution of the ionic liquid.

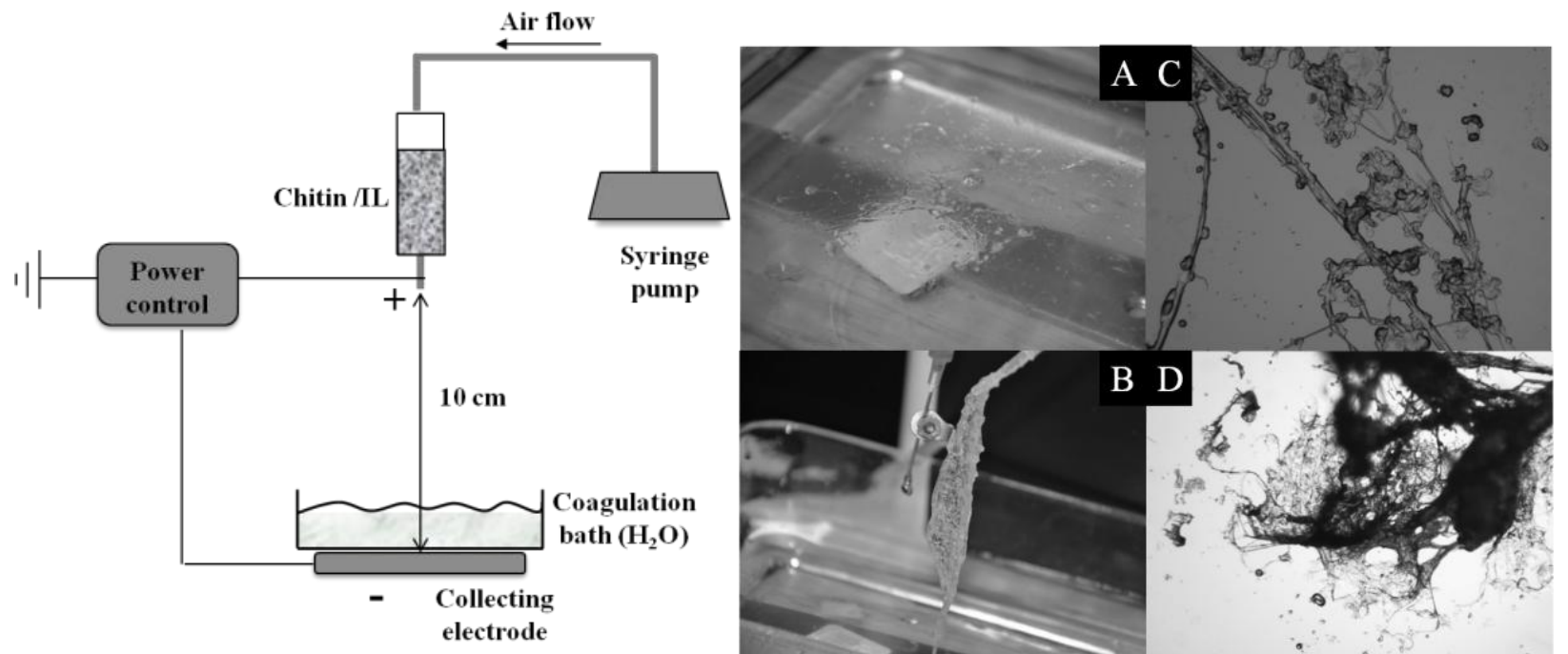

Figure 4. Schematic representation of electrospinning from IL solutions (left). Photograph and micrographs of chitin materials from Trial 1. A: chitin mat on water surface, B: Pulling the chitin mat from the surface of the water, C: fibers, beads and beaded fibers, D: dried chitin mat (right).

Our electrospinning set-up, shown in Figure 4 (left), consists of a software controlled highvoltage power supply connected to a needle (the spinneret) and an electrode under the coagulation bath (the collector). The needle is attached to a syringe through which the shrimp shell solution is delivered by compression of air pressure from a syringe pump. Water has been used as the coagulation solvent due to its ability to precipitate chitin from the IL. During electrospinning, the syringe is loaded with the appropriate solution, the potential is applied, software-controlled, and the flow is controlled by the syringe pump.

The results of our electrospinning experiments with shrimp shell and commercial chitin (hereafter PG chitin) as well as our investigation of the effects of viscosity, concentration, and 
voltage on electrospinning are reported in Table 1 below. Using our set-up, we were able to electrospin chitin nanofibers from solutions of PG chitin and shrimp shell in $\left[\mathrm{C}_{2} \mathrm{C}_{2} \mathrm{Im}\right][\mathrm{OAc}]$ and $\left[\mathrm{C}_{2} \mathrm{mim}\right][\mathrm{OAc}]$ (Figure 5). This is the first instance of electrospinning chitin from a highmolecular weight source of chitin, due to the difficulty in finding an appropriate solvent that will dissolve the biopolymer. We also measured the viscosities of various chitin solutions in ILs and determined the optimum viscosity range for electrospinning.
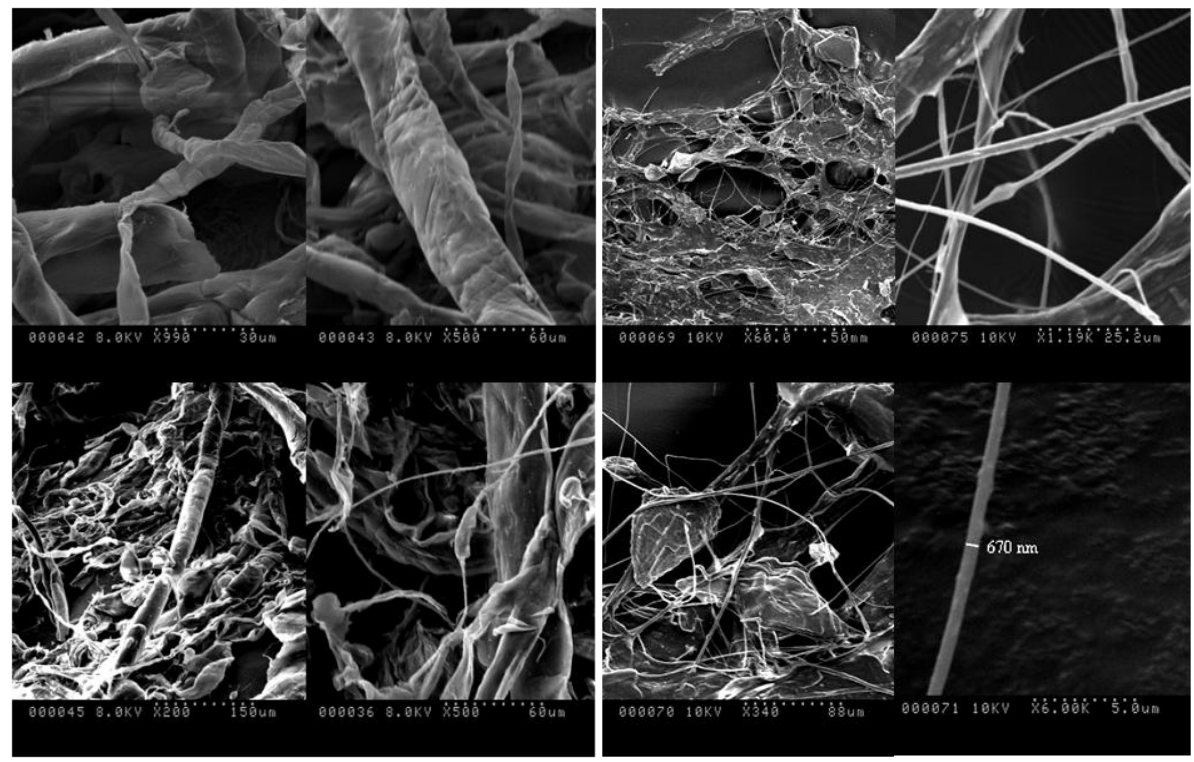

Figure 5. Electrospun nanofibers of PG-chitin from a solution of PG-chitin in $\left[\mathrm{C}_{2} \mathrm{C}_{2} \mathrm{Im}\right][\mathrm{OAc}]$ (left), and from a shrimp shell extract in $\left[\mathrm{C}_{2} \mathrm{mim}\right][\mathrm{OAc}]$ (right). 
Table 1. Important parameters and conditions for electrospinning and electrospraying including choice of IL, concentration, chitinous sample, voltage, needle size, flow rate, materials formed, and observations.

\begin{tabular}{|c|c|c|c|c|c|c|c|}
\hline Trial & Ionic Liquid & $\begin{array}{c}\text { Conc. } \\
(\mathbf{w t} \%)\end{array}$ & $\begin{array}{c}\text { Chitin } \\
\text { Type }\end{array}$ & $\begin{array}{c}\text { Voltage } \\
(\mathbf{k V})\end{array}$ & $\begin{array}{c}\text { Needle } \\
(\mathbf{G})\end{array}$ & $\begin{array}{c}\text { Air flow } \\
(\mathbf{m L / m i n})\end{array}$ & Materials formed and observations \\
\hline 1 & {$\left[\mathrm{C}_{2} \mathrm{C}_{2} \mathrm{Im}\right][\mathrm{OAc}]$} & 1.5 & PG-Chitin & 28 & 18.5 & 0.05 & $\begin{array}{c}\text { Electrospraying/electrospinning } \\
\text { Non-consistent fiber formation of } \\
\text { beaded fibers. Size mostly micron, but } \\
\text { some nanofibers. }\end{array}$ \\
\hline 2 & {$\left[\mathrm{C}_{2} \mathrm{C}_{2} \mathrm{Im}\right][\mathrm{OAc}]$} & 1.5 & PG-Chitin & 28 & 16.5 & Gravity & $\begin{array}{c}\text { Electrospinning, more consistent fiber } \\
\text { formation with significant } \\
\text { deformations on surface of fibers. } \\
\text { Sizes from smaller micron to } \\
\text { nanofibers. }\end{array}$ \\
\hline 4 & {$\left[\mathrm{C}_{2} \mathrm{C}_{2} \mathrm{Im}\right][\mathrm{OAc}]$} & 3 & $\begin{array}{c}\text { Shrimp } \\
\text { shell } \\
\text { extract }\end{array}$ & 28 & 16.5 & $\begin{array}{c}\text { Gravity/ } \\
\text { (loading) }\end{array}$ & $\begin{array}{c}\text { Phase transformations resulted in } \\
\text { solution coagulating within needle and } \\
\text { stopping flow. }\end{array}$ \\
\hline 5 & {$\left[\mathrm{C}_{2}\right.$ mim][OAc] } & $\begin{array}{c}2 \\
\text { (loading) }\end{array}$ & $\begin{array}{c}\text { Shrimp } \\
\text { shell } \\
\text { extract }\end{array}$ & 28 & 16.5 & 0.05 & $\begin{array}{c}\text { Electrospraying/electrospinning fibers } \\
\text { and membranes. Large needle caused } \\
\text { too much solution at a time }\end{array}$ \\
\hline & $\begin{array}{c}\text { Shrimp } \\
\text { shell } \\
\text { extract }\end{array}$ & 20 & 18.5 & 0.5 & $\begin{array}{c}\text { Electrospinning nano and micron sized } \\
\text { fibers. Smooth continuous fibers }\end{array}$ \\
\hline
\end{tabular}

Using IR spectroscopy, powder X-ray diffraction, and scanning electron microscopy, it was determined that a $2 \mathrm{wt} \%$ shrimp shell loading in $\left[\mathrm{C}_{2} \mathrm{mim}\right][\mathrm{OAc}]$ produces nanofibers of chitin with the best morphological properties.

In summary, chitin nanofibers were produced by electrospinning chitin directly from an extract solution of $2 \mathrm{wt} \%$ shrimp shell loading in $\left[\mathrm{C}_{2} \mathrm{mim}\right][\mathrm{OAc}]$. The results from this study demonstrated a simple method for producing high surface area chitin fibers directly from biomass in a one pot system. This is the first instance of electrospinning chitin directly from a shrimp shell/IL solution with or without auxiliary solvents, demonstrating a viable process from a renewable feedstock. The results suggest that the successful electrospinning reported here can be attributed to the ability of $\left[\mathrm{C}_{2} \mathrm{mim}\right][\mathrm{OAc}]$ to extract higher molecular weight chitin directly from shrimp shells (as previously postulated by our group ${ }^{88}$ ). This extract provided the optimal viscosity, concentration, and necessary entanglement density required for the electrospinning of smooth, continuous chitin nanofibers. 


\section{Coagulation of Chitin and Cellulose from 1-Ethyl-3-methylimidazolium Acetate Ionic- Liquid Solutions Using Carbon Dioxide.}

Barber, P. S.; Griggs, C. S.; Gurau, G.; Liu, Z.; Li, S.; Li, Z.; Lu, X.; Zhang, S.; Rogers, R. D. Coagulation of Chitin and Cellulose from 1-Ethyl-3-methylimidazolium Acetate Ionic-Liquid Solutions Using Carbon Dioxide. Angew. Chem. Int. Ed. 2013, 52, 12350-12353.

Separation of the extracted chitin from the ionic liquid solutions is a crucial step in the development of chitin materials from this natural source of shrimp shell waste. Our group has previously reported the dissolution of cellulose, ${ }^{9}$ wood pulp, ${ }^{10}$ and chitin ${ }^{8}$ using ionic liquids. With each example the coagulation solvent for the biomass was water or ethanol. These coagulation solvents must be able to solubilize the ionic liquid and allow for the precipitation of the biomass from the solution. However, in order for recycling of the ionic liquid, the coagulation solvent must be separated from the ionic liquid, in these cases, through distillation of high boiling solvents. This energy intensive process is economically unsound and in order to use the myriad of materials that could come from renewable resources such as chitin, the ease and cost of separating the ionic liquid must be explored.

We recently reported the chemisorption of $\mathrm{CO}_{2}$ in 1-ethyl-3-methylimidazolium acetate $\left(\left[\mathrm{C}_{2} \mathrm{mim}\right][\mathrm{OAc}]\right)$ through chemical reaction of an in situ carbene with $\mathrm{CO}_{2}$ and isolated crystalline $\left[\mathrm{C}_{2} \mathrm{mim}\right]\left[\mathrm{H}(\mathrm{OAc})_{2}\right]\left[\mathrm{C}_{2} \mathrm{mim}^{+}-\mathrm{COO}^{-}\right] .{ }^{11}$ Formation of the zwitterion produces one mole of acetic acid, which hydrogen bonds with the strongest acceptor, any remaining acetate anion. Since super-critical carbon dioxide $\left(\mathrm{scCO}_{2}\right)$ is inexpensive, non-explosive, highly available, easy to remove from extracted products, and is considered to be the most suitable fluid in supercritical processes, ${ }^{12-15}$ we explored whether $\mathrm{scCO}_{2}$ (or even $\mathrm{CO}_{2(\mathrm{~g})}$ ) could be used as a coagulation solvent for biopolymer IL solutions. We hypothesized that if $\mathrm{CO}_{2}$ reacted with $\left[\mathrm{C}_{2} \mathrm{mim}\right]$ [OAc], even when a biopolymer was dissolved in it, the biopolymer would precipitate and the IL could be recycled easily through the stoichiometric addition of water (Scheme 2).

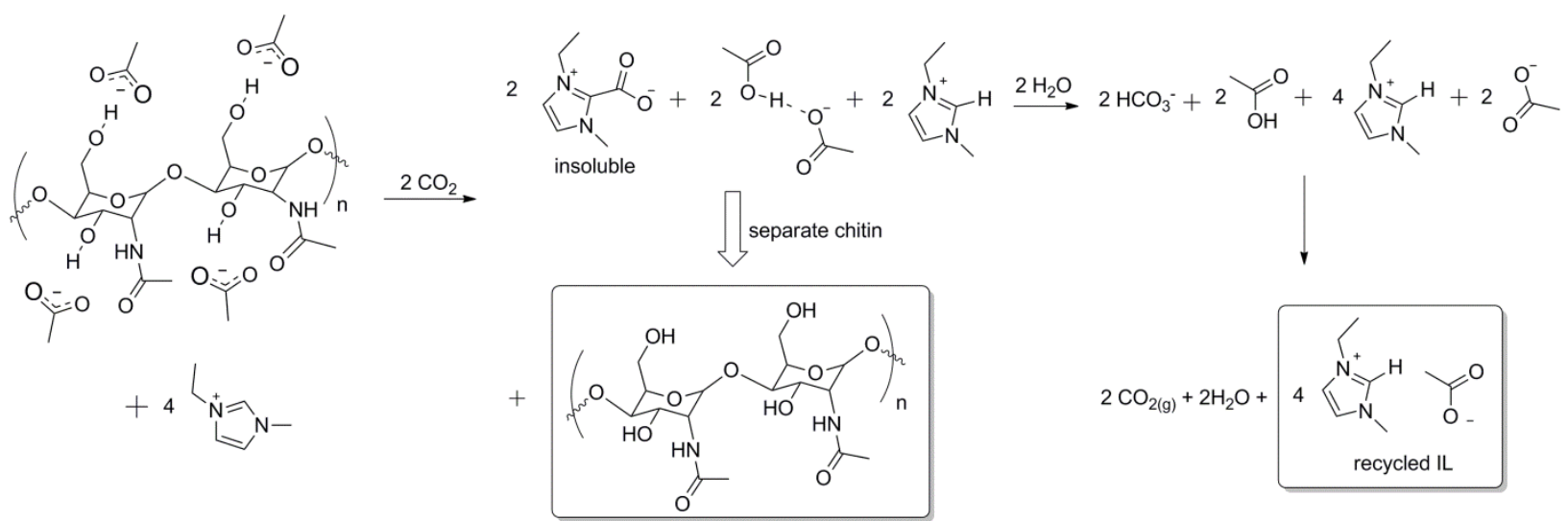

Scheme 2. Formation of a carboxylate zwitterion, ${ }^{11}$ from the chemisorption of $\mathrm{CO}_{2}$ with $\left[\mathrm{C}_{2} \mathrm{mim}\right][\mathrm{OAc}]$, produces acetic acid which competes for solubilizing acetate anions resulting in precipitation of chitin from the solution. Addition of water produces bicarbonate which reacts with acetic acid to regenerate $\left[\mathrm{C}_{2} \mathrm{mim}\right][\mathrm{OAc}]$.

A solution of chitin extracted from dried shrimp shell $(0.6 \mathrm{~g})$ with $\left[\mathrm{C}_{2} \mathrm{mim}\right][\mathrm{OAc}](29.4 \mathrm{~g})$ was prepared using a microwave process similar to the solutions prepared for electrospinning. 
Aliquots of the extract solution (5-6 g) were then loaded into a high pressure windowless reactor at room temperature, the reactor purged and filled with $\mathrm{CO}_{2(1)}$ to $6.2 \mathrm{MPa}$, and then sealed. The batch reactor was heated to $35-40{ }^{\circ} \mathrm{C}$ increasing the pressure to 7.6-10.3 $\mathrm{MPa}$, above the critical pressure. Separate samples were contacted with $\mathrm{scCO}_{2}$ for 1,2 , or $4 \mathrm{~h}$. After depressurization, a phase boundary was observed across the fluid interface (Fig. 6b). The film initially inhibited the release of $\mathrm{CO}_{2}$ from the IL-rich phase until overcome by the gas pressure (Figure 6c). The solid film was then physically removed from the IL surface using forceps.

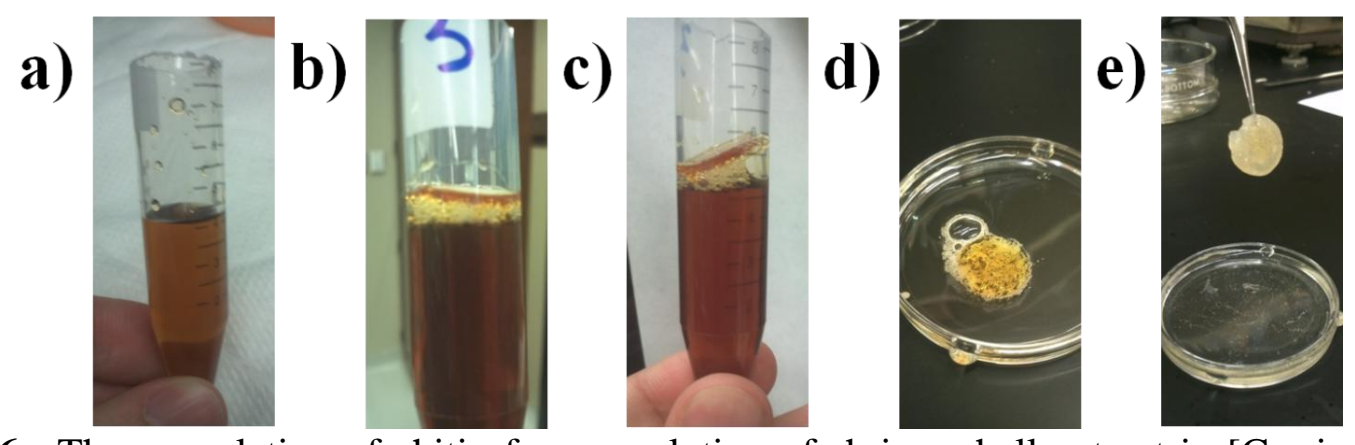

Figure 6. The coagulation of chitin from a solution of shrimp shell extract in $\left[\mathrm{C}_{2} \mathrm{mim}\right][\mathrm{OAc}]$. The extract solution (a), the coagulated chitin film (b), the coagulated chitin film being lifted by the pressure of the gas (c), the film once placed in water (d), and the chitin film removed from water (e).

The adhering IL was easily removed from the chitin by minimal water addition during which $\mathrm{CO}_{2}$ effervescence was observed (Figure $6 \mathrm{~d}$ ). (The addition of water as a purification step was employed only to remove IL for measurement of recovery yields and could be exchanged for thermal or physical separation in the process design.) The chitin (Figure 6e) was dried to constant weight and the absence of IL was confirmed by IR (Figure 7, left). The yields based on the mass recovered and the available chitin in the shrimp shells $(22 \pm 1 \%)$ were $19 \pm 4 \%(1 \mathrm{~h}$ contact), $21 \pm 6 \%(2 \mathrm{~h})$, and $20 \pm 7 \%(4 \mathrm{~h})$. We previously reported that using water as the coagulation solvent, up to $94 \%$ of the available chitin could be recovered. ${ }^{8}$ The low yield here and the observation of gas trapped in the IL-rich phase of the solution beneath the film led us to hypothesize that further coagulation was prevented by limited mass transfer and reaction only at the fluid interface.

Two different chitin solutions were compared, one from direct extraction of $2 \mathrm{wt} \%$ dried shrimp shell and a second by dissolution of $1.75 \mathrm{wt} \%$ of regenerated chitin (previously extracted and coagulated). Approximately 5-6 g samples of each were loaded into the reactor and pressurized with $\mathrm{CO}_{2}$ for $1 \mathrm{~h}$ as described above. The samples were then weighed to measure the amount of $\mathrm{CO}_{2}$ absorbed, followed by removal of the surface film.

This entire process was repeated until the entire solution was solidified, which depending on the solution was 5-7 times. Each film was washed with a minimal volume of water to remove the residual IL ( $c a .7 \%$ of the original IL volume per film) and dried to constant weight for yield determination. Infrared spectroscopy indicated each sequential film was of equal purity and quality.

Figure 7, right, summarizes the cumulative chitin recovery and the mass of chitin coagulated for each sequential $1 \mathrm{~h}$ contact time. The mass of chitin recovered after each $1 \mathrm{~h}$ contact was 5.1 $\pm 0.9 \mathrm{mg}$ and $10 \pm 2 \mathrm{mg}$ for the shrimp shell extract and regenerated chitin solutions, respectively, indicating that coagulation in this batch reactor was indeed limited to the fluid 
interface. Nonetheless, $95 \%$ of the available chitin in the shrimp shells was recovered from the extract solution (ca. $0.45 \%$ chitin in solution) and $57 \%$ of the chitin in the much more concentrated regenerated chitin solution $(1.75 \%)$ after $5 \times 1 \mathrm{~h}$ contacts. We believe the higher recoveries from the extract solution are due to the presence of other dissolved material from the shrimp shells (e.g., $\mathrm{CaCO}_{3}$ ) which would reduce the number of free acetate anions available to dissolve the chitin.
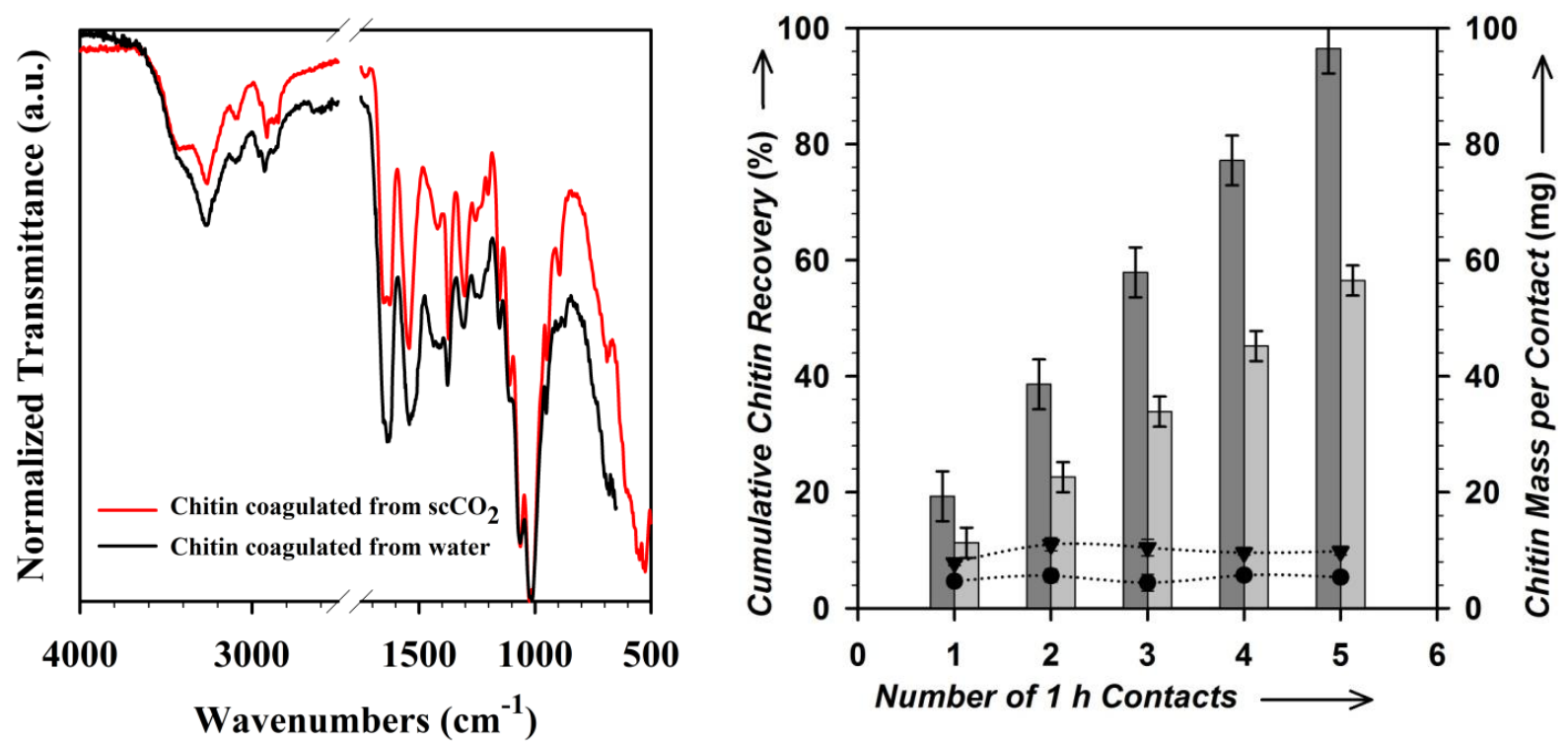

Figure 7. IR spectroscopy of chitin coagulated with $\mathrm{scCO}_{2}$ compared to chitin coagulated with water (left). Cumulative chitin recoveries (left axis, bars) and mass of chitin recovered per $1 \mathrm{~h}$ contact (right axis, $\cdots$ ) from solutions of chitin extracted from shrimp shells (dark grey and •) and regenerated chitin (light grey and $\boldsymbol{\nabla}$ ). Error bars are from triplicate measurements (right).

Overall, we have demonstrated that the chemisorption of $\mathrm{CO}_{2}$ is a viable mechanism for coagulation of chitin and cellulose dissolved in $\left[\mathrm{C}_{2} \mathrm{mim}\right][\mathrm{OAc}]$ using $\mathrm{scCO}_{2}$ and $\mathrm{CO}_{2(\mathrm{~g})}$ through the zwitterionic imidazolium carboxylate that sequesters the acetate anions from the system thus precipitating the biopolymer. The advantage of using $\mathrm{scCO}_{2}$ over $\mathrm{CO}_{2(\mathrm{~g})}$ is a cleaner, densitybased physical separation, where the less dense chitin remains at the liquid interface, while the more dense crystalline $\left[\mathrm{C}_{2} \mathrm{mim}\right]\left[\mathrm{H}(\mathrm{OAc})_{2}\right]\left[\mathrm{C}_{2} \mathrm{mim}^{+}-\mathrm{COO}^{-}\right]$settles to the bottom. This densitybased separation might be amenable to continuous processing, however, because ILs are not generally soluble in $\mathrm{CO}_{2},{ }^{16}$ removal of all residual IL from the precipitated biopolymer remains a significant challenge.

The use of $\mathrm{CO}_{2}$ chemisorption as an alternative coagulating process has the potential to provide an economical and energy efficient method for recycling the IL by eliminating the need to distill higher boiling coagulation solvents from the IL, or at least reducing the amount of antisolvent which must be removed. For example, in our unoptimized proof of concept, only ca. $34 \%$ of the IL (residual IL which was washed from the chitin films after $\mathrm{scCO}_{2}$ coagulation) would require removal of liquid antisolvent (here water) to be recycled. Even this, however, can be greatly improved upon using other low energy techniques we are currently exploring. Clearly the continuing challenge will be balancing the energetic cost of IL recycle with the economic value of the biopolymer. While perhaps not the final answer, and with many engineering parameters to be determined, this coagulation route should be considered when $\left[\mathrm{C}_{2} \mathrm{mim}\right][\mathrm{OAc}]$ or closely related ILs are chosen as the biopolymer dissolution solvent. 


\section{Surface Modification of Chitin Fibers Spun from Ionic Liquid Solution: A Versatile Platform with the Strength of Chitin and the Surface Functionality of Chitosan.}

Barber, P. S.; Kelley, S. P.; Griggs, C. S.; Wallace, S.; Rogers, R. D. (In preparation as a full article for Green Chem.)

Using the development of the chemistry needed to append an amidoxime to an amine group (Section III-A), we sought to append amidoxime onto chitin using a similar procedure. As concurrent with the electrospinning development, we opted to use dry wet-jet spun chitin fibers as previously prepared for both ease of preparation and easy to scale up.

Since not only biodegradability but cost were motivating factors ${ }^{17}$ for using chitin material, a decision was made to use the raw extracted chitin in a one pot process, rather than extracting the chitin, purifying it via coagulation in water, and then redissolving the chitin prior to use. From prior work, we anticipated that this could lead to higher amounts of impurities in the fibers (see below) and some sacrifice in overall strength. ${ }^{8}$ Nonetheless, the simplicity of this process or some small variation of it would keep chemical and energy usage to a minimum.

The four types of chitin fibers in this study were all prepared from a single batch of shrimp shell spinning solution. The spinning solution was prepared by extraction of ca. $19 \mathrm{~g}$ dried shrimp shell $(6 \mathrm{wt} \%)$ in $\left[\mathrm{C}_{2} \mathrm{mim}\right][\mathrm{OAc}]$ followed by centrifugation to remove any undissolved residue. The extract solution was then loaded into four $60 \mathrm{~mL}$ syringes which were degassed in an oven at $80{ }^{\circ} \mathrm{C}$ overnight. Each syringe was used to dry-jet wet spin a spool of about $1 \mathrm{~g}$ of chitin fibers using techniques and equipment we have previously reported for chitin and cellulose $^{8,18}$ Each spool of chitin fibers was washed with DI water and further soaked for 1-2 days to remove any residual IL. One spool of the chitin fibers (designated SS fibers) was removed and air dried in air, while the remaining spools were kept in water until used in the next step.

Surface modification of the chitin fibers followed the reaction pathways noted in Scheme 1 taking advantage of the insoluble nature of chitin. First, three spools of SS fibers were taken off the spools, placed in separate beakers, and each stirred in $400 \mathrm{~mL}$ of $1.25 \mathrm{M}$ aqueous $\mathrm{NaOH}$ at $80{ }^{\circ} \mathrm{C}$ for $8 \mathrm{~h}$ to deacetylate the surface. The reaction solution was decanted from the fibers which were then washed three times with $100 \mathrm{~mL}$ DI water. Approximately $1 \mathrm{~g}$ of the fibers (designated as DA fibers) were set aside for analysis and the remaining fibers were carried on to the next step.

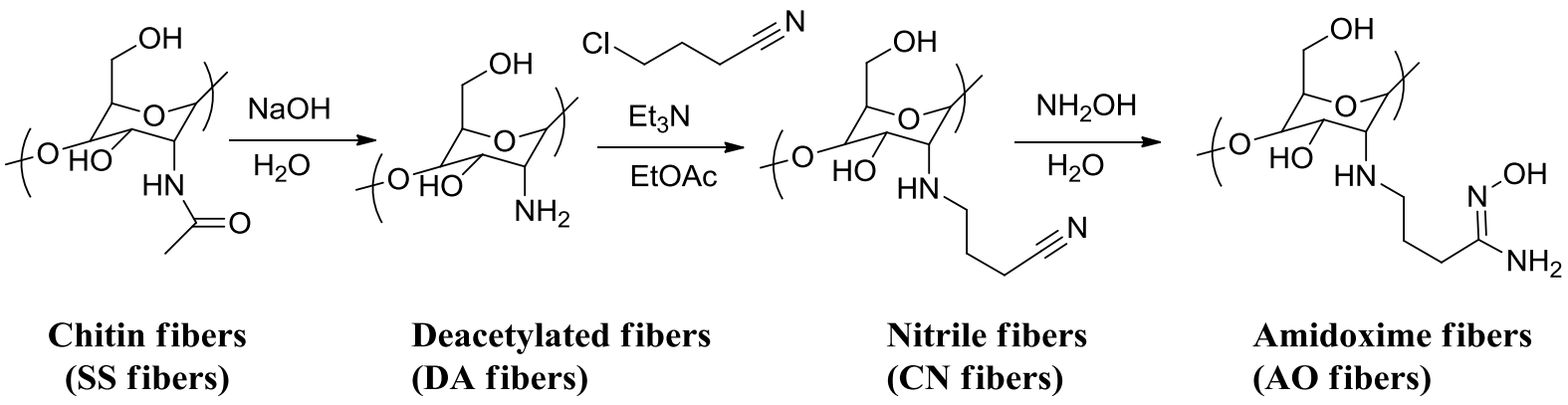

Scheme 3. Synthetic scheme for the surface modification of chitin fibers using a typical method for deactylation of chitin and a chemical route described above to append amidoxime groups onto imidazolium cations. 
To attach the uranyl-selective amidoxime ligand to the now free amine groups on the chitin fiber surface, a two-step reaction was conducted. Two $\sim 1 \mathrm{~g}$ portions of the DA fibers in separate beakers were stirred in an ethyl acetate solution containing $0.0155 \mathrm{M}$ 4-chlorobutyronitrile and $0.0160 \mathrm{M}$ triethylamine at $50{ }^{\circ} \mathrm{C}$ overnight. The reaction solutions were then decanted and each set of fibers was washed three times with $50 \mathrm{~mL}$ ethyl acetate resulting in the nitrilefunctionalized fibers (designated $\mathrm{CN}$ fibers). An approximately $1 \mathrm{~g}$ portion of the $\mathrm{CN}$ fibers were air dried and kept for analysis. The other $\sim 1 \mathrm{~g}$ portion of $\mathrm{CN}$ fibers were then stirred in $0.047 \mathrm{M}$ aqueous hydroxylamine at $80{ }^{\circ} \mathrm{C}$ overnight. The solution was decanted and the fibers were washed three times with DI water to provide the amidoxime-functionalized fibers (designated AO fibers).

Chemical characterization of the resulting fibers was conducted through chitin content measurement, thermogravimetric analysis (TGA), infrared (IR) spectroscopy, X-ray photoelectron spectroscopy (XPS), and distribution experiments with $\mathrm{UO}_{2}$. Physical characterization of the fibers was determined through TGA and tensile strength measurements.

Table 2. Composition and physical properties of shrimp shells and modified fibers.

\begin{tabular}{|c|c|c|c|c|c|}
\hline & $\begin{array}{c}\text { Shrimp } \\
\text { Shells }\end{array}$ & $\begin{array}{c}\text { SS } \\
\text { Fibers } \\
\end{array}$ & $\begin{array}{c}\text { DA } \\
\text { Fibers } \\
\end{array}$ & $\begin{array}{c}\text { CN } \\
\text { Fibers } \\
\end{array}$ & $\begin{array}{c}\text { AO } \\
\text { Fibers } \\
\end{array}$ \\
\hline Chitin Content $^{\mathrm{a}}(\%)$ & $22(1)$ & $58.3(5)$ & $64(3)$ & $61.8(2)$ & $63.2(8)$ \\
\hline Moisture Content ${ }^{\mathrm{b}}(\%)$ & 4.0 & $7(2)$ & $4(1)$ & $4(2)$ & $4(1)$ \\
\hline $\mathrm{CaCO}_{3}$ Content $^{\mathrm{b}}(\%)$ & 26 & $16.9(2)$ & $23.6(1)$ & $29(1)$ & $26(2)$ \\
\hline Residual $^{\mathrm{c}}(\%)$ & 47 & $17(1)$ & $9(1)$ & $3(3)$ & $5(1)$ \\
\hline Decomposition ( $\left.\mathbf{T}_{5 \% \text { onset }},{ }^{\circ} \mathrm{C}\right)$ & - & $274(4)$ & 226 & $229(8)$ & $265(1)$ \\
\hline Fiber Diameter (mm) & - & $0.20(5)$ & $0.20(3)$ & $0.25(3)$ & $0.24(2)$ \\
\hline Break Stress (MPa) & - & $9(2)$ & $9(3)$ & $9(3)$ & $7(1)$ \\
\hline Break Elongation (\%) & - & $6(3)$ & $6(2)$ & $7(2)$ & $5(2)$ \\
\hline Yield Stress (MPa) & - & $7(2)$ & $5(2)$ & $4(3)$ & $4(1)$ \\
\hline Yield Elongation (\%) & - & $2(1)$ & $2(1)$ & $2(1)$ & $2(1)$ \\
\hline Young's modulus (MPa) & - & $3(1)$ & $2(1)$ & $2(1)$ & $2(1)$ \\
\hline
\end{tabular}

${ }^{\mathrm{a}}$ Chitin content determined by the Black and Schwartz method. ${ }^{19} 23{ }^{\mathrm{b}}$ Determined gravimetrically. ${ }^{\mathrm{c}}$ Determined by mass balance.

The chitin content of the dried shrimp shell waste and each type of fiber were measured by the Black and Schwartz method revealing chitin contents of 22(1), 58.3(5), 64(3), 61.8(2), and 63.2(8)\% for shrimp shell and SS, DA, CN, and AO fibers, respectively (Table 2). The large increase in chitin content for the fibers when compared to the initial chitin content of the dried shrimp shells was expected since the IL extracts chitin while leaving most of the shell matrix behind as previously reported. ${ }^{8}$ The $\mathrm{CaCO}_{3}$ content of each fiber was determined using the decomposition of $\mathrm{CaCO}_{3}$ at $700{ }^{\circ} \mathrm{C}$ by calculating mass loss as $\mathrm{CO}_{2}$. Values of 16.9(2), 23.6(1), 29(1), and 26(2)\% $\mathrm{CaCO}_{3}$ were determined for SS, DA, CN, and AO fibers, respectively (Table 2). The relative increase in $\mathrm{CaCO}_{3}$ content for the surface treated fibers is most likely due to the removal of proteins by the $\mathrm{NaOH}$ treatment as discussed above. 
IR spectroscopy was used to study the surface of the fibers by placing them directly on the surface of the ATR sample window, as well as to study the bulk material by grinding the fibers prior to measurement. A detail of the normalized spectra of the unground fibers are presented in

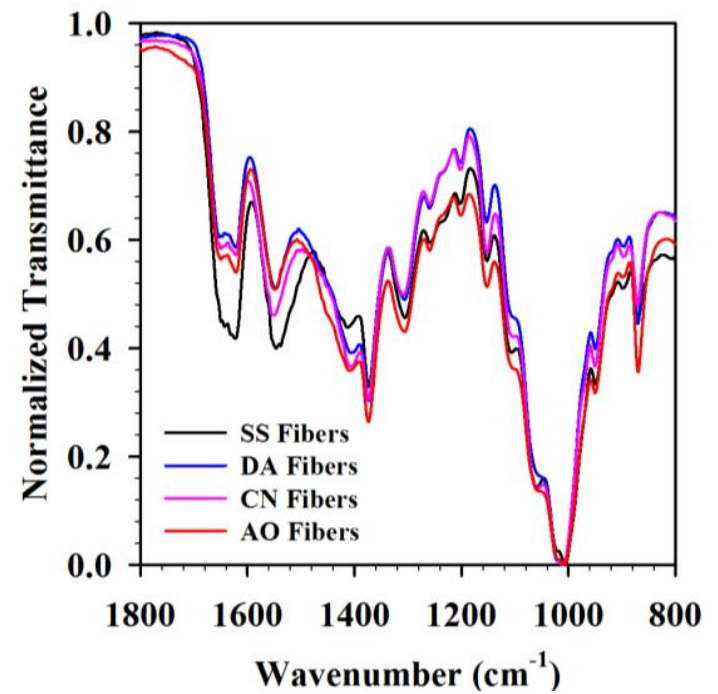

Figure 8. Detail of normalized IR spectra of unground fiber surface of SS (black), DA (blue), $\mathrm{CN}$ (pink), and AO (red) fibers.
Figure 8. All whole fibers show similar spectra characteristic of chitin with subtle, yet significant, differences. With treatment of the SS fibers, a few changes in the spectra are noteworthy. Within the lower range of $1200-$ $1800 \mathrm{~cm}^{-1}$ the most significant changes are from the decrease and sharpening of the bands at 1650 and $1631 \mathrm{~cm}^{-1}$, as well as the increase in intensity of the band at $1420 \mathrm{~cm}^{-1}$. Both changes are indicative of a change in the deacetylation of the material, and the most significant changes occur with the treatment to prepare the DA fibers which, as indicated in the chitin content measurement, resulted in a bulk composition change.

To characterize the interior part of the fiber which was not exposed to the treatment baths, the fibers were dried and ground to a fine particle size and the $\mathbb{R}$ was recorded using the same parameters as the unground fibers. The spectra of the ground fibers are shown in Figure 9, along with the spectra of ground shrimp shells and $\mathrm{CaCO}_{3}$ for comparison. Overall, the spectra of the ground SS fibers are similar to the spectra of the unground fibers indicating the bulk material and surface are similar and characteristic of chitin as expected. Significant differences between ground and unground $\mathrm{DA}, \mathrm{CN}$, and $\mathrm{AO}$ fibers are observed as shown by the large increase in the band at $\sim 1400 \mathrm{~cm}^{-1}$. When compared to the overlaid spectrum of $\mathrm{CaCO}_{3}$, the data suggests an increase in the relative $\mathrm{CaCO}_{3}$ concentration with the first treatment of fibers (to make DA fibers), which is also consistent with the removal of some protein material in the deactylation step. This corresponds well to the TGA and chitin content measurement data presented above, which also indicating that the deacetylation treatment removes protein and perhaps small amount of chitin. The differences also indicate that the chemical reactivity of the surfaces and interiors of the fibers are indeed different.

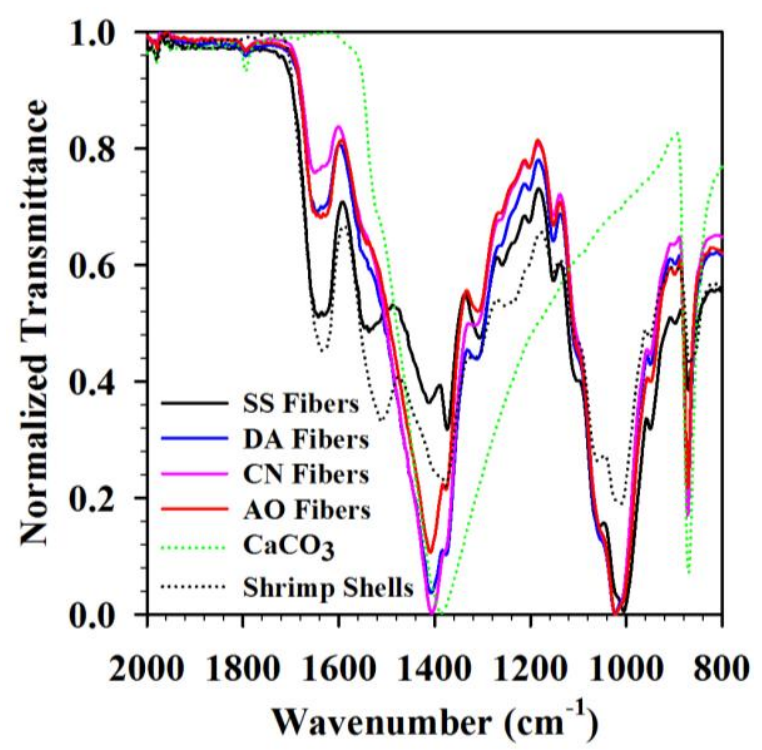

Figure 9. Detail of normalized IR spectra from ground SS (black), DA (blue), CN (pink), and AO (red) fibers, dried shrimp shells (dotted black), and $\mathrm{CaCO}_{3}$ (dotted green). 
For additional surface characterization, X-ray photoelectron spectroscopy (XPS) was performed on the unground fibers. Peaks were assigned based on reference data from the PHI Handbook of X-Ray Photoelectron Spectroscopy. ${ }^{20}$ All fibers were first surveyed through a wide-scan to determine the elements present within the top 1-12 $\mathrm{nm}$ of the surface of the samples (Figure 10, left). Carbon, N, and $\mathrm{O}$ were found as expected for chitin, with additional peaks for $\mathrm{Ca}$ and $\mathrm{Na}$ for certain fibers. Both $\mathrm{DA}$ and $\mathrm{CN}$ fibers appear to contain $\mathrm{Na}$ which would indicate the fibers were not washed sufficiently after treatment with $\mathrm{NaOH}$. The AO fibers do not contain $\mathrm{Na}$, indicating the final treatment within water was significant enough to remove the final traces of $\mathrm{Na}$.
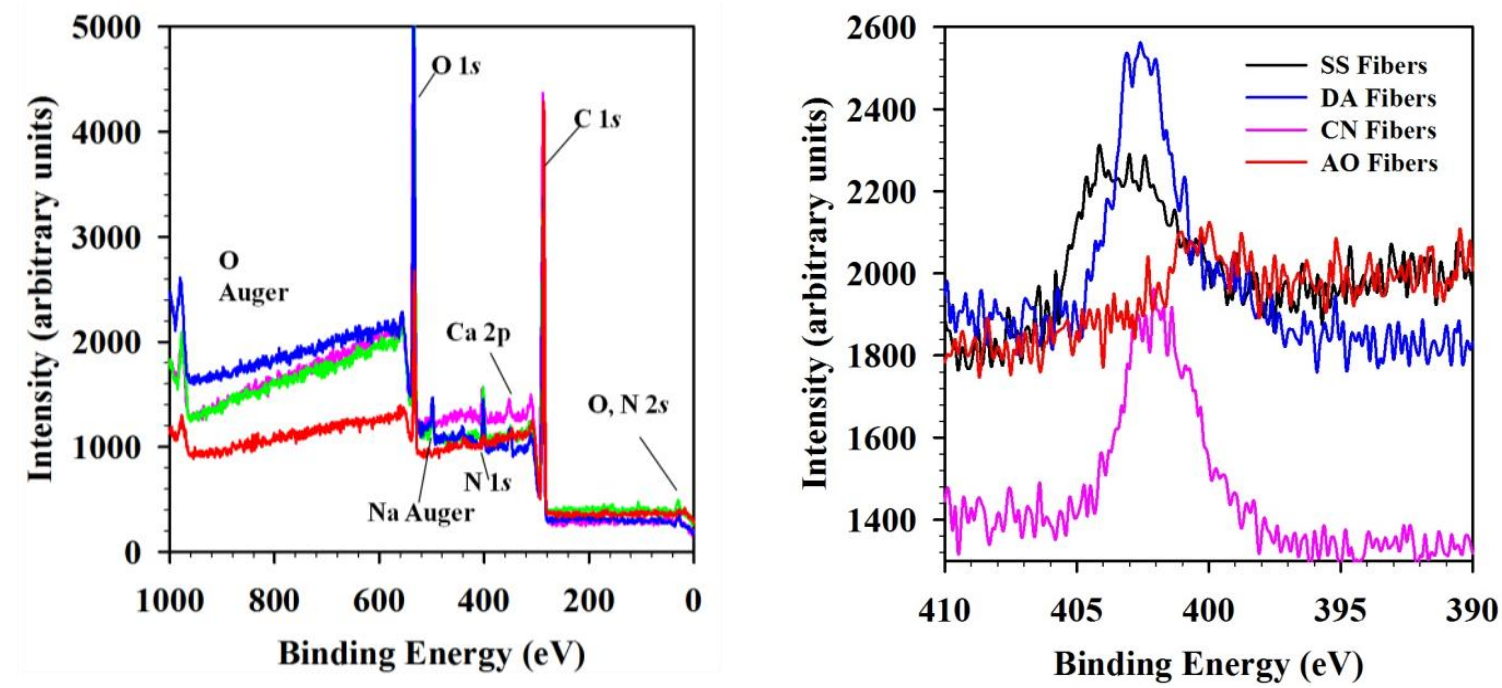

Figure 10. Assigned XPS survey scans for SS, DA, CN, and AO Fibers (left) and high resolution XPS scans of N1s region for SS, DA, CN, and AO Fibers (right).

A high resolution scan within the $\mathrm{N} 1 s$ region of the spectrum $(390-410 \mathrm{eV}$, shown in Figure 10 , right) indicated significant changes within the surface of the fibers. The $\mathrm{N} 1 s$ peak for DA fibers is sharper and at slightly lower binding energy than the $\mathrm{N} 1 s$ peak for DA fibers. As the natural chitin in SS fibers typically contains a certain amount of free amine (or chitosan), the broader $\mathrm{N} 1 s$ peak probably contains contributions from two types of nitrogen atoms, acetylated and deacetylated. Upon deacetylation, the broad peak sharpened and moved slightly to lower binding energy, indicating that there is now one type of nitrogen atom, and it is more reduced than the nitrogen atoms in natural chitin. Both of these observations are consistent with deacetylation. Further treatment to the $\mathrm{CN}$ did not significantly alter the peak present in the DA fibers, though it does appear to broaden slightly which would indicate two nitrogen types, a second amine and a nitrile. Final treatment to the amidoxime severely broadened the $1 \mathrm{~N} s$ peak, which might be expected considering this fiber surface now has three nitrogen atom types; a secondary amine, a primary amine, and oxime.

To determine the uranium uptake efficiency, of the surface modification of the chitin fibers we measured the distribution ratios of the fibers using ${ }^{233} \mathrm{U}$ at infinite dilution. Each of the four types of fibers was tested for their ability to remove $\mathrm{UO}_{2} \mathrm{Cl}_{2}$ from very dilute aqueous solution. Dry weight distribution ratios were determined radiometrically at $25(1){ }^{\circ} \mathrm{C}$ by batch contacts of ca. $2.5 \mathrm{mg}$ of each fiber with $1 \mathrm{~mL}$ of DI water spiked with ca. $0.007 \mu \mathrm{Ci}$ of ${ }^{233} \mathrm{UO}_{2} \mathrm{Cl}_{2}$ shaken for $144 \mathrm{~h}$, with aliquots taken for counting at certain intervals. Dry weight distribution ratios $\left(D_{w}\right)$ for each fiber were calculated from the change in activity using eq. 1 . 


$$
\mathrm{D}_{\mathrm{w}}=\left(\frac{A_{o}-A_{f}}{A_{f}}\right)\left(\frac{m L_{(a q)}}{m_{R}(d w c f)}\right)
$$

where $\mathrm{A}_{0}$ is the count rate in solution prior to contact with the resin, $\mathrm{A}_{\mathrm{f}}$ is the count rate in solution after contact with the resin, $\mathrm{V}$ is the volume $(\mathrm{mL})$ of solution in contact with the resin, $\mathrm{m}_{\mathrm{R}}$ is the mass $(\mathrm{g})$ of wet resin, and the dry weight conversion factor (dwcf) allows conversion to the dry mass of resin.
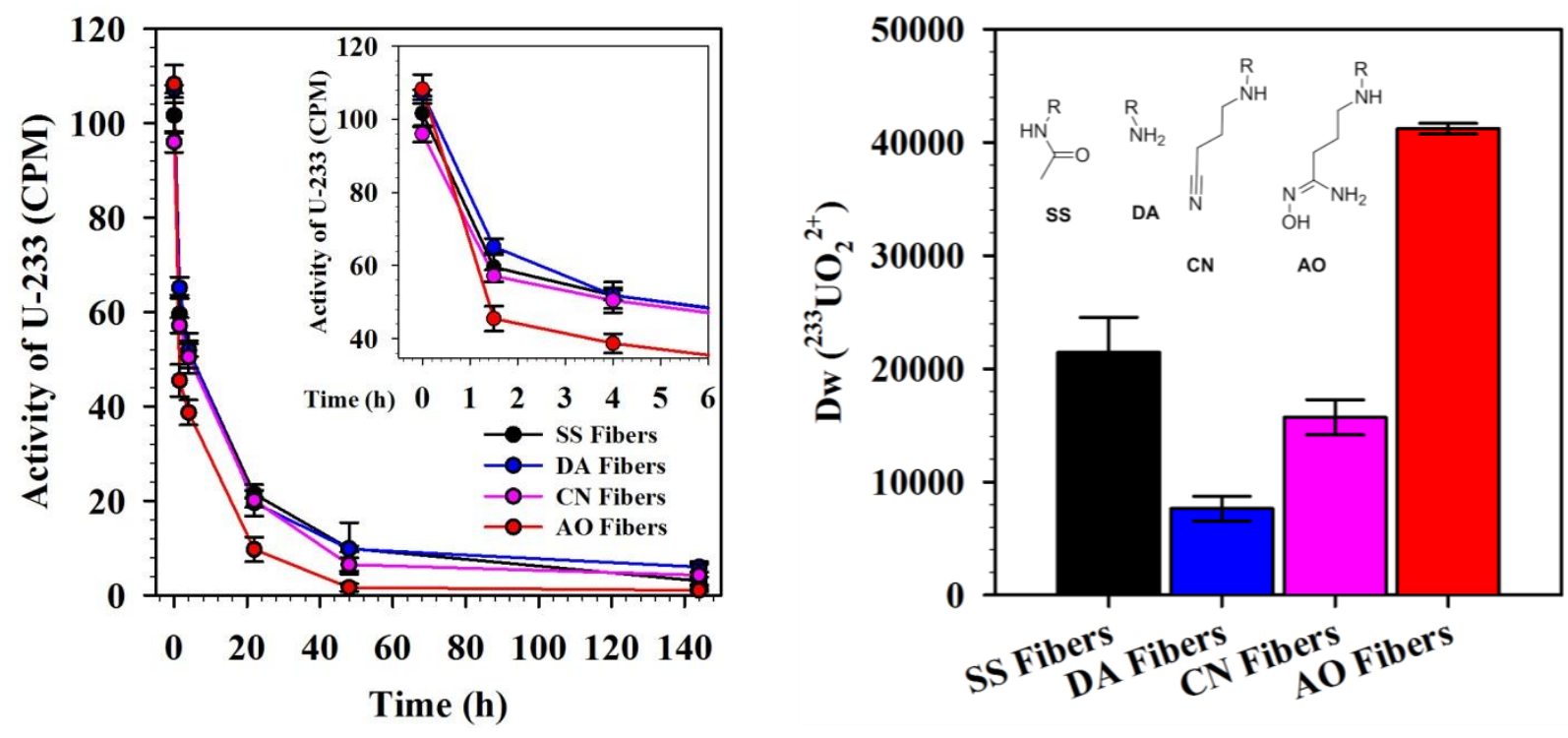

Figure 11. Activity of ${ }^{233} \mathrm{UO}_{2} \mathrm{Cl}_{2}$ as a function of time for SS, DA, CN, and AO Fibers (left). $\mathrm{D}_{w}$ values for extraction of ${ }^{233} \mathrm{UO}_{2} \mathrm{Cl}_{2}$ from water by SS, DA, CN, and AO fibers (right).

Upon addition of the spiked solution to the fibers, aliquots were taken at 1.5, 4, 22, 44, and $144 \mathrm{~h}$. The plot of activity as a function of time is shown in the Figure 11 (left) and shows an exponential decrease in the activities of the samples. AO fibers show the fastest uptake when compared to the other fibers. The differences in the $D_{w}$ values (Fig. 11, right) indicate that each treatment affected uranium uptake, supporting surface functionalization. The AO fibers show the highest affinity for $\mathrm{UO}_{2}{ }^{2+}$, commensurate with the known affinity of the amidoxime functional group for aqueous uranyl ions. The distribution ratios for the other fibers correlate with the hardness of the coordinating/functional group: $\mathrm{SS}$ (amide) $>\mathrm{CN}$ (nitrile) $>\mathrm{DA}$ (amine).

We have prepared chitin fibers using a dry wet-jet spinning process from the direct extraction of chitin from shrimp shells using ionic liquids. By exploiting the insolubility of natural chitin, we have developed a platform for surface modification of chitin materials. Building upon traditional methods for deacetylation, which provides access to the primary amine, we have modified the surface of chitin fibers with a selective extractant (here, amidoxime for the extraction of uranium from seawater), leaving an inner core of chitin that represents the bulk material. The complete compositional analysis and physical properties suggest that surface modification does not significantly alter the bulk properties of the material.

We consider this a platform for functional biorenewable absorbents that through the use of surface-appended selective extractants, provides both the high strength of natural chitin along with the functional properties of synthetically tailored materials. 


\section{E. Extraction of uranium from seawater using surface modified chitin fibers; in collaboration with PNNL.}

Fibers prepared through wet-jet spinning were surface modified and sent to PNNL for seawater testing. The fibers sent were chitin (SS), deacetylated (DA), and amidoxime (AO) fibers. A time trial experiment was measured (every 7 days) on the AO fibers and a one point trial (56 days).

While running the experiment, it was noting that during the course of the experiment the SS fibers essentially "disappeared," signifying a decomposition. The others did not and appeared unchanged after the 56 days. The observations indicate that the SS fibers are biodegradable under seawater conditions and with a small amount of surface treatment (DA and AO), we can extend the time in which they degrade.

The capacities are shown in the graph below (Figure 12). The values are low at $3.48 \mathrm{ug} \mathrm{U} / \mathrm{g}$ ads for $\mathrm{AO}, 3.26 \mathrm{ug} \mathrm{U} / \mathrm{g}$ ads for DA, and $0.37 \mathrm{ug} \mathrm{U} / \mathrm{g}$ ads. It appears the kinetics are relatively fast with no significant uptake after 7 days. We believe that the low values support our surface modification hypothesis, as we have modified a surface that had low surface area to begin with. Therefore, by making a high surface area material we will greatly increase the capacity. The SS fiber sample is so low due to the low amount of adsorbent remaining within the experiment with decomposition.

Therefore seawater trials indicated two important results for our materials; 1) Surface modification was successful and increasing the surface area through using electrospun nanofibers would greatly increase the capacity and 2) the chitin-based fibers are biodegradable and with surface modification the time frame of biodegradation can be increased to beyond a typical deployment time.

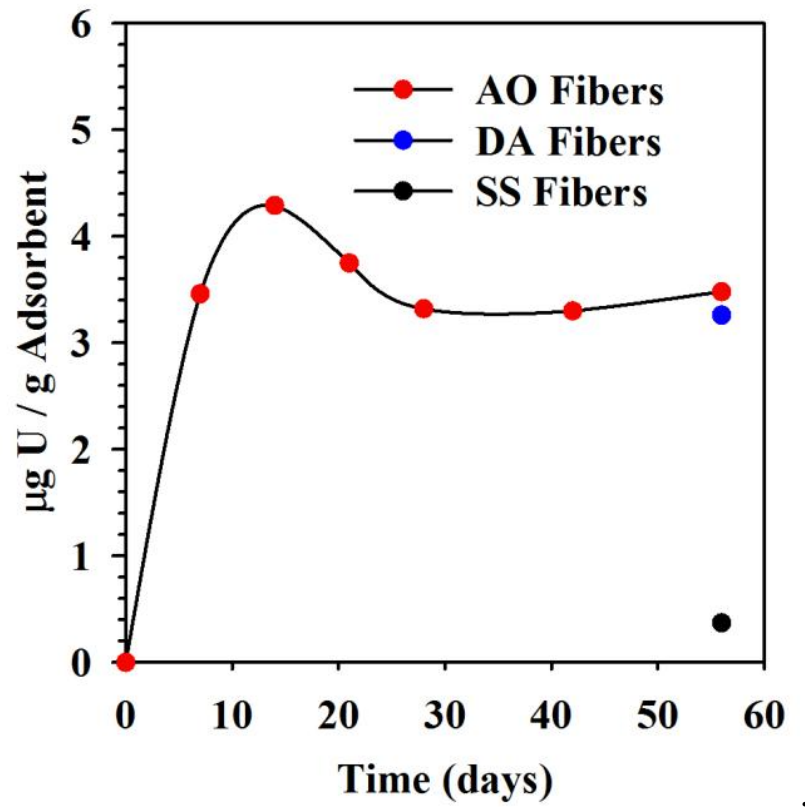

Figure 12. Uranium capacities of SS (black), DA (blue), and $\mathrm{AO}$ (red) fibers in seawater as a function of number of days. 


\section{F. Scale up and development of continuous chitin extraction using flow through microwave.}

Our feedstock of shrimp shells was obtained from a recently build seafood waste drying/pulverizing facility in Bayou Le Batre, LA, which was established under the auspices of the Alabama Farmers Market Authority. ${ }^{21}$ The facility accepts shellfish waste from local fishermen and processing plants. Shellfish waste is pressed to remove some protein and water and fed through a fluidized bed dryer to obtain the dried crustacean shells used as our starting material. Shrimp shells are known to contain $\sim 15-25 \%$ chitin (Figure 13), 30-40\% $\mathrm{CaCO}_{3}$, $30-40 \%$ proteins, and small amounts of other compounds such as astaxanthin. ${ }^{22}$ We have measured the chitin content of shrimp shells obtained from this process to be $22( \pm 1) \%$ by the standard method. ${ }^{23}$
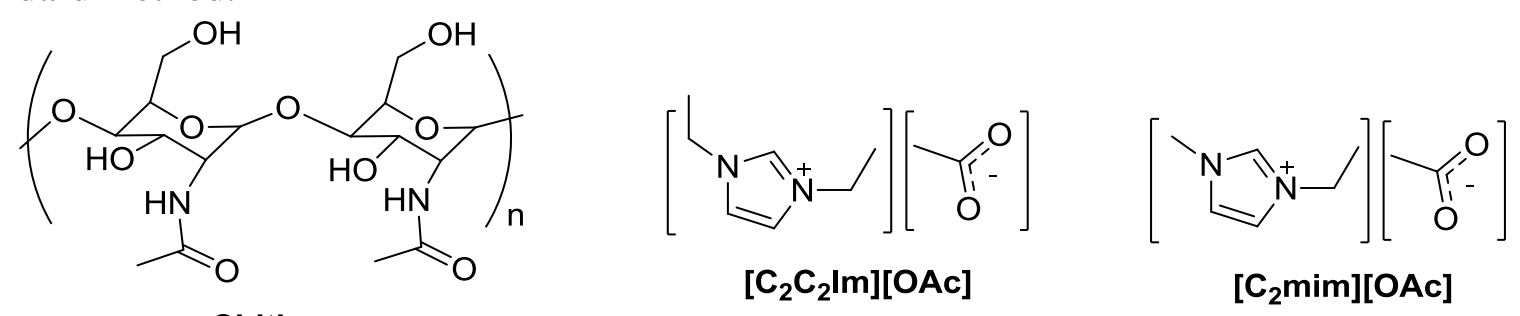

Figure 13. Structures of chitin and the ionic liquids used for the dissolution and extraction of chitin from shrimp shells.

Two ionic liquids 1-ethyl-3-methylimidazolium acetate $\left(\left[\mathrm{C}_{2} \mathrm{mim}\right][\mathrm{OAc}]\right)$ and 1,3diethylimidazolium acetate $\left(\left[\mathrm{C}_{2} \mathrm{C}_{2} \mathrm{Im}\right][\mathrm{OAc}]\right.$, were found to effectively dissolve PG chitin and shrimp shell using the microwave dissolution method reported by our group. ${ }^{8}$ Through the use of a standard domestic microwave we can process up to $18 \mathrm{~g}$ shrimp shell waste with $282 \mathrm{~g}$ ionic liquid and approximately 4 minutes of microwave heating.

Scaling our efforts towards a continuous microwave dissolution process, we acquired and

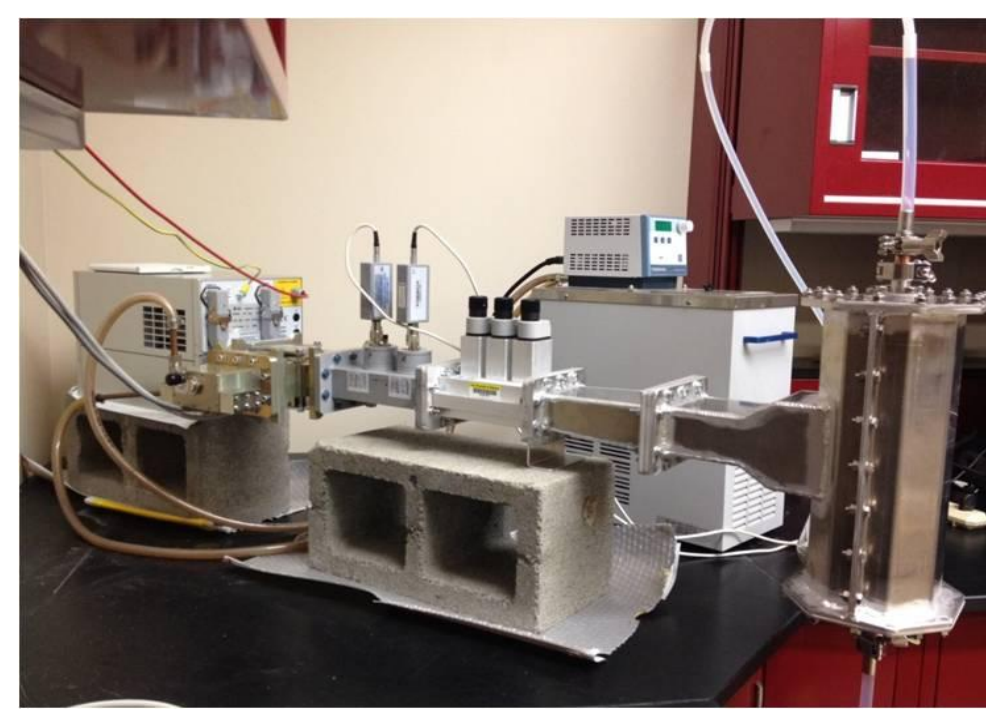

Figure 14. High-throughput microwave for batch and continuous microwave dissolution and extraction of chitin from shrimp shells. setup a high-throughput $2 \mathrm{~kW}$ continuous microwave cylindrical heating system from Industrial Microwave Systems, Inc (Figure 14). A trial run at the manufacturer's plant with $10 \mathrm{~kg}$ of diethylimidazolium acetate $\left(\left[\mathrm{C}_{2} \mathrm{C}_{2} \mathrm{Im}\right] \mathrm{OAc}\right)$ indicated that the IL will absorb the microwaves efficiently (99.9\%+) and can be run in a continuous fashion. The IL was fed into the unit at a rate of 1 $\mathrm{gal} / \mathrm{min}$ and using only $23 \%$ of the microwave power, a temperature of $82{ }^{\circ} \mathrm{C}$ was reached in just $120 \mathrm{sec}$. This temperature would be sufficient to achieve the dissolution of waste shells, without degrading 
the IL. To ensure that the IL can be recycled and reused without any major loss, the trial also involved the recirculation of the IL for several cycles, and no obvious degradation was observed.

Using this setup, we were able to successfully extract chitin from up to 30 grams of shrimp shells into ionic liquids in several minutes. An external batch of shrimp shell and ionic liquid was cycled through the setup several times to dissolve the shrimp shells. This indicates that a batch process is viable for large scale extraction of chitin from shrimp shell waste in minimal time using a low energy microwave dissolution process. Adaptation to a continuous process is conceivable by continuously adding shrimp shell and IL to the feed while removing and filtering the IL solution. Continuous processing would utilize different parameters; therefore our goal is for the continuous extraction of chitin from shrimp shell waste. This is critical for the extraction of the raw chitin from waste shells and this microwave is capable of processing approximately $50 \mathrm{~L} / \mathrm{h}$ of waste shell/IL solution. The continuous microwave system enables the liquid to be uniformly and volumetrically heated on a continuous flow basis, eliminating the problem of hot spots encountered with traditional surface-heating technologies. Since no one has yet used this equipment with ILs and biomass, we are continuing to investigate the appropriate safe conditions for continuous processing. Current development in this goal is the full investigation of the key engineering parameters needed to design and build a batch reactor for a $3 \mathrm{~L}$ scale dissolution of shrimp shells into ionic liquid.

\section{Summary of Major Achievements}

Successful demonstrations and achievements for this objective are tabulated below:

- Demonstration of the dissolution of gram to 10s of gram amounts of shrimp shell in ionic liquids using both a domestic and industrial microwave ovens within minutes.

- Coagulation of chitin from alkylimidazolium acetate ionic liquids using gaseous and super-critical carbon dioxide through the formation of a carboxylate zwitterion and the precipitation of chitin from the solution.

- Demonstration for the first time of the electrospinning of chitin into micron to nano sized fibers from a solution of chitin extracted from the dissolution of shrimp shells in ionic liquids.

- Demonstration of the coordination mechanism of amidoxime to the uranyl ion through the synthesis and study of hydrophobic ionic liquids functionalized with amidoxime.

- Successful demonstration of the surface modification of chitin fibers with amidoxime spun from a solution of shrimp shell extract in ionic liquid.

- Demonstration of uranium uptake from aqueous solutions through infinite dilution experiments using ${ }^{233} \mathrm{U}$.

- Demonstration of the extraction of uranium from seawater using surface modified chitin fibers.

- Demonstration of the biodegradation of chitin fibers in seawater conditions. 


\section{Collaborations}

Through collaborations within the working group of the project, we have increased the accomplishments based on the objectives. We are currently in collaboration with Dr. Eric Schneider at The University of Texas-Austin to prepare an initial cost analysis of the extraction of uranium from seawater using chitin fibers as the adsorbent. We have hosted Dr. Schneider's graduate assistant, Harry Lindner, at The University of Alabama to share the full details of the chitin adsorbent production as well as other options for preparation of the adsorbent, deployment in the oceans, and recovery of the uranium from the adsorbent.

\section{Publications}

1. Barber, P. S.; Griggs, C. S.; Wallace, S.; Rogers, R. D. Surface Modification of Chitin Fibers Spun from Ionic Liquid Solution: A Versatile Platform with the Strength of Chitin and the Surface Functionality of Chitosan, in preparation as a full article for Green Chem.

2. Barber, P. S.; Griggs, C. S.; Gurau, G.; Liu, Z.; Li, S.; Li, Z.; Lu, X.; Zhang, S.; Rogers, R. D. Coagulation of Chitin and Cellulose from 1-Ethyl-3-methylimidazolium Acetate IonicLiquid Solutions Using Carbon Dioxide. Angew. Chem. Int. Ed. 2013, 52, 12350-12353.

3. Barber, P. S.; Shamshina, J. L.; Rogers, R. D. A "green" industrial revolution: Using chitin towards transformative technologies. Pure Appl. Chem. 2013, 85, 1693-1701.

4. Barber, P. S.; Griggs, C. S.; Bonner, J. R.; Rogers, R. D. Electrospinning of chitin nanofibers directly from an ionic liquid extract of shrimp shells. Green Chem. 2013, 15, 601-607.

5. Barber, P. S.; Kelley, S. P.; Rogers, R. D. Highly selective extraction of the uranyl ion with hydrophobic amidoxime-functionalized ionic liquids via $\eta 2$ coordination. $R S C A d v . \mathbf{2 0 1 2}, 2$, 8526-8530.

\section{Presentations}

1. "Using an Ionic Liquid Platform for the Development of Materials for the Extraction of Uranium from Seawater" Barber P. S.; Griggs, C. S.; Kelley, S. P.; Wallace, S.; Rogers, R. D. Presented before the 5th Congress on Ionic Liquids (April 21-24, 2013) in Vilamoura, Portugal

2. "Ionic liquids and strategic metals: Challenges and opportunities" Robin D. Rogers, the $244^{\text {th }}$ American Chemical Society's National Meeting and Exposition (August 21, 2012) in Philadelphia, PA

3. "Extraction of uranium with regenerated chitin from the dissolution of shrimp shells in ionic liquid" Robin D. Rogers, Patrick S. Barber, Chris S. Griggs, Steven P. Kelley, and Gabriela Gurau. Presented before the $244^{\text {th }}$ American Chemical Society's National Meeting and Exposition (August 20, 2012) in Philadelphia, PA

4. "Amidoxime functionalized materials for the selective extraction of the uranium" Patrick S. Barber, Steven P. Kelley, Chris S. Griggs, and Robin D. Rogers. Presented before the $244^{\text {th }}$ American Chemical Society's National Meeting and Exposition (August 21, 2012) in Philadelphia, PA

5. "Electrospun chitin nanofibers for uranyl adsorbant materials" Chris S. Griggs, Patrick S. Barber, Steven P. Kelley, Gabriela Gurau, and Robin D. Rogers. Presented before the $244^{\text {th }}$ 
American Chemical Society's National Meeting and Exposition (August 21, 2012) in Philadelphia, PA

6. Organization of "Uranium from seawater" session at $244^{\text {th }}$ American Chemical Society's National Meeting and Exposition (August 19-23, 2012) in Philadelphia, PA

7. "Ionic Liquids for Extraction and Functionalization of Uranium Selective Chitin Sorbents" Robin D. Rogers, Patrick S. Barber, Chris S. Griggs, Erica L. Stoner, and Steven P. Kelley, Presented by G. Gurau before the 2012 Materials Research Society Spring Meeting \& Exhibit (April 9-13, 2012), San Francisco, CA, Abstract BBB 6.3. (Invited Speaker)

8. "Optimization and Evaluation of Uranium Sorptive Bio-materials" Christopher S. Griggs, Steven L. Larson, John H. Ballard, Patrick S. Barber, and Robin D. Rogers, October 24, 2011, The 17th Symposium on Separation Science and Technology, Gatlinburg, TN

9. "Design and Coordination of f-elements with Amidoxime-Functionalized Ionic Liquids" Patrick S. Barber, Steven P. Kelley, and Robin D. Rogers, October 24, 2011, The 17th Symposium on Separation Science and Technology, Gatlinburg, TN

\section{Media}

Audio/Video:

1. "Advances in decades-old dream of mining seawater for uranium," (video) August 21, 2012, ACS Live, http://www.ustream.tv/recorded/24868811

2. Christopher Intagliata, "Nanofibers Extract Uranium from Seawater" (podcast) August 22, 2012, Scientific American Podcast

3. "Harvesting uranium from seawater" (video)The Chicago Tribune, http://www.chicagotribune.com/videogallery/71974432//Harvesting-uranium-fromseawater

4. "Shrimpers And Uranium" (radio) As it Happens with Carol Off and Jeff Douglas, The Wednesday Edition, August 22, 2012, http://www.cbc.ca/asithappens/episode/2012/08/22/the-wednesday-edition-41/

Articles:

1. "Uranium from seawater idea boosted with shrimp shells", August 22, 2012 Science \& Environment, BBC, www.bbc.co.uk

2. "The sea is the key to uranium bounty" August 23, 2012, World Nuclear News, www.world-nuclear-news.org

3. Adrian Bishop, "Nuclear power from uranium in seawater gets closer" August 21, 2012, The Earth Times, www.earthtimes.org

4. Swagato Chakravorty, "Innovations in Uranium Mining, Extracting Uranium from Seawater" August 23, 2012, Energy and Capital, www.energyandcapital.com

5. Frances White, "Fueling nuclear power with seawater" August 21, 2012, R \& D Magazine, www.rdmag.com

6. Mark Prigg, "Are oceans the future of nuclear power? Scientists move closer to extracting uranium from seawater" August 22, 2012, Daily Mail, www.dailymail.co.uk

7. John von Radowitz, "Sea uranium extraction 'close to economic reality" August 21, 2012 The Independent, www.independent.co.uk

8. Pete Sheehan, "Energy from seawater" August 22, 2012 Science and Technology, www.journal-news.net 
9. Francie Diep, "Scientists could soon begin extracting nuclear fuel from seawater" August 22, 2012, The Christian Science Monitor, CSMonitor.com

10. "Uranium from seawater said attainable goal" August 21, 2012, United Press International, Inc., www.upi.com

11. "Oceans could be the future of nuclear power: scientists," August 21, 2012, Zany Science, The Hindustan Times, www.hindustantimes.com

12. "Mining' uranium from seawater moves a step closer," August 22, 2012, The Scotsman, www.Scotsman.com

\section{References}

$1 \quad$ Drab, D. M.; Smiglak, M.; Shamshina, J. L.; Kelley, S. P.; Schneider, S.; Hawkins, T. W.; Rogers, R. D. New J. Chem. 2011, 35, 1701.

2 Vukovic, S.; Watson, L. A.; Kang, S. O.; Custelcean, R.; Hay, B. P. Inorg. Chem. 2012, 51, 3855-9.

3 Meli, L.; Miao, J.; Dordick, J. S.; Linhardt, R. J. Green Chem. 2010, 12, 1883-1892.

4 D. Li and Y. Xia, Advanced Materials, 2004, 16, 1151-1170.

5 J. D. Schiffman and C. L. Schauer, Polymer Reviews, 2008, 48, 317-352.

6 S. Fridrihk, J. Yu, M. Brenner, and G. Rutledge, Phys. Rev. Lett., 2003, 90, 144502.

7 L. Meli, J. Miao, J. S. Dordick, and R. J. Linhardt, Green Chem. 2010, 12, 1883-1892.

8 Y. Qin, X. Lu, N. Sun, R. D. Rogers, Green Chem. 2010, 12, 968-971.

$9 \quad$ Swatloski, R. P.; Spear, S. K.; Holbrey, J. D.; Rogers, R. D. J. Am. Chem. Soc. 2002, 124, 4974-4975.

10 Sun, N.; Rahman, M.; Qin, Y.; Maxim, M. L.; Rodríguez, H.; Rogers, R. D. Green Chem. 2009, 11, 646-655.

11 Gurau, G.; Rodríguez, H.; Kelley, S. P.; Janiczek, P.; Kalb, R. S.; Rogers, R. D. Angew. Chem. Int. Ed. 2011, 50, 12024-12026.

12 S. Keskin, D. Kayrak-Talay, U. Akman, Ö. Hortaçsu, J. Supercrit. Fluids 2007, 43, 150-180.

13 H. Machida, M. Takesue, R. L. Smith, J. Supercrit. Fluids 2011, 60, 2-15.

14 P. T. Anastas, J. C. Warner, Green Chemistry: Theory and Practice, Oxford University Press, New York, 1998.

15 P. T. Anastas, J. B. Zimmerman, Environ. Sci. Technol. 2003, 37, 94A-101A.

16 L. A. Blanchard, D. Hancu, E. J. Beckman, J. F. Brennecke, Nature 1999, 399, 28-29

17 E. Schneider and D. Sachde, Cost and Uncertainty Analysis of an Adsorbent Braid System for Uranium Recovery from Seawater. Technical Report / DOE sub-contract 00114954, Austin: The University of Texas at Austin; United States Department of Energy, 2011

18 Sun, N.; Swatloski, R. P.; Maxim, M. L.; Rahman, M.; Harland, A. G.; Haque, A.; Spear, S. K.; Daly, D. T.; Rogers, R. D. J. Mat. Chem. 2008, 18, 283-290.

19 Black, M. M.; Schwartz, H. M. The Analyst 1950, 75, 185.

20 J. F. Moulder, JW. F.;. Stickle, W. F.;P. E. Sobol, P. E.; and K. D. Bomben, K. D. Handbook of X-Ray Photoelectron Spectroscopy. G. Muilenberg (ed J. Chastain (ed), Perkin-Elmer: Corp., Physical Electronics Division, Eden Praire, MN, 1992.

21 Gulf Coast Agricultural and Seafood Coop Seafood By-Products Processing Facility, EDA Investment No. 0401-06250. http://blog.al.com/live/2010/05/seafood_waste_recycling_plant.html (Accessed 06/04/10).

22 Rodde, R. H.; Einbu, A.; Varum, K. Carbohydr. Polym. 2008, 71, 388-393. 